\title{
From Cross-Cultural Economic Experiments to Experimental Indigenous Management Research - A Suggestion
}

\section{Sven Horak}

\author{
St. John's University, USA
}

ABSTRACT This study provides an overview, categorization, and integration of what has been achieved in the niche of cross-culture experimental economics (CCEE) so far, aiming to inspire indigenous management researchers to extend their methodological toolbox by including experimental methods. As a result of the review, I find that most of the early studies lack depth and contextualization as well as detailed explanation about why human behavior differs. Hence, a better understanding about the influence of culture on economic decision-making is rather limited if it cannot be explained in more detail. In contrast, deep contextualization is a principle in indigenous management research (IMR). Both have so far not benefited from each other in the study of how culture affects human behavior, as both currently develop in parallel. Following the call for high-quality IMR (Tsui, 2004), this paper argues that an experimental methodology can make a contribution to IMR in the future by drawing on the strengths of both IMR (i.e., contextualization) and CCEE (i.e., methodology).

KEYWORDS contextualization, culture, experimental economics, indigenous management research, research methods

\section{INTRODUGTION}

Cross-cultural studies are a niche area in experimental economics that has made considerable advances in the past two decades in terms of better understanding the influence of culture on economic decision-making (van Witteloostuijn, 2015). The widely believed advantage of experimentation is that it provides empirical results based on decisions that are directly affected by monetary rewards (incentives). Hence, incentivized experiments are believed to trigger intrinsically motivated behavior to a much higher extent than, for instance, questionnaire-based surveys would do (Roth, 1995; Smith \& Walker, 1993). A further advantage is that factors that influence decision-making behavior can be controlled and the data gathering itself can be replicated at the same or in different places (labs) or by using subject 
pools from different countries (Binmore \& Shaked, 2010; Gächter, 2009; Ottone, Ortona, Ponzano, \& Scacciati, 2010; Weber \& Camerer, 2006). By observing the decision-making behavior of test persons from different countries who are tested under the same conditions, observed behavioral differences are often attributed to the influence of cultural differences. However, although the field has progressed, as we will see in the course of this paper, nevertheless cross-cultural experimental research in economics still faces limits of explanatory depth to explain why culturally-induced behavioral differences occur. Conventionally, behavioral differences are often interpreted en bloc as cultural differences. As a result, they explain little about the distinctive characteristics that lead to the observed differences. In recent crosscultural experimental economics (CCEE), a call for a deeper understanding of the factors that has led to those differences has arisen (Chuah, Hoffmann, Jones, \& Williams, 2007; Oosterbeek, Sloof, \& Van De Kuilen, 2004).

Whereas van Witteloostuijn (2015) provides convincing reasons for the application of experiments in the field of International Business (IB), this study focuses more on the micro-level of human behavior relevant for cross-cultural research in the field of international management, particularly indigenous management research. The purpose of this study is first and foremost to introduce indigenous management scholars to studies conducted in the field of CCEE. I do not aim to produce a complete literature review of the study of culture in the economic discipline. Rather I intend to present experimental applications and insight and outline methodological advantages that I propose to merge with traditional approaches to indigenous management research in order to propose advancement from a methodological point of view. By doing so, I first aim to generate an understanding about the state of research in the field of CCEE by focusing on the question of what CCEE has contributed to the understanding of culture. Further, based on the latter, I debate how Indigenous Management Research (IMR) and CCEE can mutually benefit by combining methodological strengths for the study of culture. I approach this question by systematically reviewing studies published in this field. Further, the results are summarized and critically discussed, and paths are proposed for advancement.

\section{LITERATURE SELEGTION AND GATEGORIZATION}

As this paper intends to review, categorize, and integrate what has been achieved in the niche of CCEE so far, articles qualify if they fulfill the following criteria. First, they must be relevant to the field of experimental economics (i.e., by applying research methods common in this discipline). Second, they must be relevant to cross-cultural economic research, namely only those articles that explicitly aim to examine culture were considered. Third, the research should have been published in an internationally recognized peer-reviewed journal.

A keyword search was undertaken in order to identify relevant articles in the first round of filtering. The following keywords were used: experiment, culture, 
cross-culture, inter-culture, values, norms, behavior, and differences. The sources used for the keyword search were Google Scholar, EconLit, Web of Knowledge, and Ideas. This search resulted in numerous relevant studies that partly included non-experimental studies or studies that did not show a direct link with the examination of cultural phenomena. In the second round of filtering, only those studies that apply an experimental methodology for the examination of culture were selected. As a result, 23 studies were selected that were published in journals including the American Economic Review, Journal of Economic Behavior E Organization, Experimental Economics, Fournal of Socio-Economics, or Fournal of Public Economics and Science (see Table 1).

Following the selection criteria described above, relevant studies were analyzed in two steps. In the first step, articles were clustered according to research design (i.e., by game application). In the second step, within each cluster, studies were sorted according to the subject of analysis, enabling the identification of the broad research streams within each cluster.

However, while operating the structured approach described above, I faced the limitations that it caused. For instance, as is conventionally done in management studies, I initially followed the popular and common 'Hofstedian' interpretation of culture, which uses country culture foremost as a proxy for culture. While this is common, it is blind on newer developments that pursue a more realistic view on culture and includes - as advanced countries become more multicultural - race, ethnicity, or religion as anchors of social identity. Thus, I complemented my approach by presenting studies that reflect newer trends and that have meaning for cross-cultural research but that were not adequately captured by our criteria. Additionally, I report about the few experimental studies conducted in management studies (Leung, Bhagat, Buchan, Erez, \& Gibson, 2005; Leung \& Su, 2004).

Further, I have added to the table information on how far the respective studies discuss questions of size effects, and where applicable null and negative findings, since this is today a common standard contrary to the past where the unexplained variance in the data was overwhelming at times and left doubts in terms of the explanatory power of this research (Lewin et al., 2016). Benchmark studies that explicitly and comprehensively discuss size effects are the studies by, e.g., Chua and Ng (2017) and in particular Gerhart (2009) on culture-related research. In order to bolster the explanatory power of the empirical findings, studies should inform how high or low the variance is and how this can be explained; discuss null and negative finding as well as to highlight the practical importance of the results. However, since especially in the field of CCEE several studies are rather explorative in nature, i.e., not guided by a set of hypotheses (e.g., Burns, 2016; Chuah et al., 2007; Chuah, Hoffmann, Ramasamy, \& Tan, 2014; Henrich et al., 2001, 2006, 2010), in many cases they are not amenable to discuss null and negative findings. 
Table 1. Rank (\#) according to citations of selected studies

\# Study

Citations

1 Henrich, J., Boyd, R., Bowles, S., Camerer, C., Fehr, E., Gintis, H., and McElreath,

R. 2001. In Search of Homo Economicus: Behavioral Experiments in 15 Small-Scale Societies. American Economic Review, 91(2), 73-78.

2 Roth, A. E., Prasnikar, V., Okuno-Fujiwara, M., and Zamir, S. 1991. Bargaining and market behavior in Jerusalem, Ljubljana, Pittsburgh, and Tokyo: An experimental study. American Economic Review, 81(5), 1068-1095.

3 Herrmann, B., Thöni, C., and Gächter, S. 2008. Antisocial Punishment Across Societies. Science, 319(5868), 1362-1367.

4 Henrich, J., McElreath, R., Barr, A., Ensminger, J., Barrett, C., Bolyanatz, A., Cardenas, J. C., et al. 2006. Costly punishment across human societies. Science, 312 (5781), 1767-70.

5 Henrich, J., Ensminger, J., McElreath, R., Barr, A., Barrett, C., Bolyanatz, A., Cardenas, J. C., et al. 2010. Markets, religion, community size, and the evolution of fairness and punishment. Science (New York, N.Y.), 327(5972), 1480-4.

6 Weimann, J. 1994. Individual behaviour in a free riding experiment. Fournal of Public Economics, 54(2), 185-200.

7 Buchan, N. R., Johnson, E. J., and Croson, R. T. A. 2006. Let's get personal: An international examination of the influence of communication, culture and social distance on other regarding preferences. Fournal of Economic Behavior \& Organization, 60 (3), 373-398.

8 Carpenter, J., Daniere, A., and Takahashi, L. 2004. Cooperation, trust, and social capital in Southeast Asian urban slums. Fournal of Economic Behavior EO Organization, 55 (4), 533-551.

9 Gächter, S., and Herrmann, B. 2009. Reciprocity, culture and human cooperation: previous insights and a new cross-cultural experiment. Philosophical Transactions of the Royal Society B Biological Sciences, 364(1518), 791-806.

10 Bohnet, I., Greig, F., Herrmann, B., and Zeckhauser, R. 2008. Betrayal Aversion: Evidence from Brazil, China, Oman, Switzerland, Turkey, and the United States. American Economic Review, 98(1), 294-310.

11 Burlando, R., and Hey, J. D. 1997. Do Anglo-Saxons free-ride more? Fournal of Public Economics, 64(1), 41-60.

12 Buchan, N., and Croson, R. 2004. The boundaries of trust: own and others? Actions in the US and China. Fournal of Economic Behavior E Organization, 55(4), 485-504.

13 Cason, T. N., Saijo, T., and Yamato, T. 2002. Voluntary Participation and Spite in Public Good Provision Experiments: An International Comparison. Experimental Economics, 5(2), 133-153.

14 Kocher, M., Cherry, T., Kroll, S., Netzer, R., and Sutter, M. 2008. Conditional cooperation on three continents. Economics Letters, 101(3), 175-178.

15 Buchan, N. R., Groson, R. T. A., and Johnson, E. J. 2004. When Do Fair Beliefs Influence Bargaining Behavior? Experimental Bargaining in Japan and the United States. Fournal of Consumer Research, 31(1), 181-190.

16 Cameron, L., Chaudhuri, A., Erkal, N., and Gangadharan, L. 2009. Propensities to engage in and punish corrupt behavior: Experimental evidence from Australia, India, Indonesia and Singapore. Fournal of Public Economics, 93(7-8), 843-851.

17 Chuah, S.-H., Hoffmann, R., Jones, M., and Williams, G. 2007. Do cultures clash? Evidence from cross-national ultimatum game experiments. Fournal of Economic Behavior \& Organization, 64(1), 35-48.

18 Hennig-Schmidt, H., Li, Z.-Y., and Yang, C. 2008. Why people reject advantageous offers - Non-monotonic strategies in ultimatum bargaining: Evaluating a video experiment run in PR China. Fournal of Economic Behavior E Organization, 65(2), $373-384$. 
Table 1. Continued

\# Study

19 Barr, A., and Serra, D. 2010. Corruption and culture: An experimental analysis. Fournal of Public Economics, 94(11-12), 862-869.

20 Barr, A., Wallace, C., Ensminger, J., Henrich, J., Barrett, G., Bolyanatz, A., Cardenas, J. C., et al. 2009. Homo aequalis: a cross-society experimental analysis of three bargaining games. Oxford, UK.

21 Chen, K., and Tang, F.-F. 2009. Cultural differences between Tibetans and ethnic Han Chinese in ultimatum bargaining experiments. European fournal of Political Economy, 25(1), 78-84.

22 Valenzuela, A., Srivastava, J., and Lee, S. 2005. The role of cultural orientation in bargaining under incomplete information: Differences in causal attributions. Organizational Behavior and Human Decision Processes, 96(1), 72-88.

23 Castro, F. M. 2008. Where are you from? Cultural differences in public good experiments. Fournal of Socio-Economics, 37(6), 2319-2329.
Citations

Source: Google Scholar (3 May 2013) and Publish or Perish (3 May 2013; Harzing, 2007)

In the following subsection, by starting with the CCEE literature, the result of each study in the respective category is presented in the form of an overview. Since the studies that I present can be regarded as the 'first major wave' of CGEE studies, they can be allocated to the decade of the early 1990s and beginning of 2000s. In that era, strategic games were most common for studying cross-cultural phenomena. I note that I provide further explanations on the most common game designs and rules in Appendices I-IV, as well as other game designs I came across in Appendix V. Moreover, I point out other applied designs in the text. The following section is succeeded by a review of newer trends in the CGEE field.

\section{Fairness and Context}

Fundamental research about fairness motives in different contexts (e.g., market versus dyadic) has been conducted, among others, by Kahneman, Knetsch, and Thaler (1986), Rabin (1993), or Fehr and Schmidt (1993). The main motivation of these early studies was first and foremost a discomfort with the very central assumption of economic behavior that proposes that 'almost all economic models assume that all people are exclusively pursuing their material self-interest and do not care about "social" goals per se' (Fehr \& Schmidt, 1999: 817). Experimental studies showed that in fact social goals do play a role, which goes against the basic assumptions manifested in the model of the homo oeconomicus. In a departure from there, scholars developed models of social preferences explicitly assuming both self-interest as well as a concern for payoffs of others (Charness \& Rabin, 2002; Fehr \& Gaechter, 2000). As a result of this work, theories have been developed further that make a case for human reciprocity behavior resulting in the development of a new species, the homo reciprocans (Bowles \& Gintis, 2002; 
Fehr \& Gaechter, 1998). In parallel to these developments, scholars became interested in the question of whether cultural factors may play a role, too. Cultureexploring studies based on the popular ultimatum game (UG, for a detailed description, see Appendix I) have been conducted by Buchan and Croson (2004), Chen and Tang (2009), Chuah et al. (2007, 2009), Hennig-Schmidt, Li, and Yang (2008), Henrich et al. (2001), Roth, Prasnikar, Okuno-Fujiwara, and Zamir (1991), and Valenzuela, Srivastava, and Lee (2005). These studies can be categorized according to three groups: (1) those that detect cultural differences with regard to norms of fairness, (2) those that analyze differences in fair beliefs, and (3) those that include further contextual factors that influence the decisionmaking behavior of individuals and groups in the inter- and cross-cultural contexts (Table 2).

The seminal work conducted by Roth et al. (1991) and Henrich et al. (2001) tests the rational-behavior assumption of homo oeconomicus and examines economic behavior in 15 (mostly tribal) societies (Henrich et al., 2001). The standard behavioral assumption of the homo oeconomicus could not be confirmed in any of the societies investigated as considerable differences in behavior between the respective cultures were observed. The participants of some tribes offered $25 \%$ or more of the stakes at play, while others offered even more than $50 \%$ of the stake. Roth et al. (1991) use a subject pool from Israel, Japan, the US, and the former Yugoslavia. Their results show that the observed differences, such as high offers made in the US and former Yugoslavia compared with the low offers made in Israel, cannot be explained by language, currency, or experimental design effects, which are considered to distort behavior (Roth, 1995), but rather by cultural differences. They conclude that behavioral differences seem to be the result of varying fairness norms.

Buchan and Croson (2004) focused on the influence of fairness concepts on negotiation behavior. In their study, the repeated UG was played in Japan and the US with fairness norms differing significantly in the countries analyzed. Americans believe that the actor with greater negotiation power should be allocated the highest payment, while the Japanese expect the actor with greater negotiation power to share the payment with the weaker actor. Further, a religious mindset may influence fairness concepts and thus differences in decision-making behavior. Chen and Tang (2009) apply the UG in order to analyze the effect of cultural factors on behavior, with particular regard to beliefs. Tibetans in Lhasa and Han Chinese in Xiamen as well as in Singapore were recruited from groups of pupils, students, and professors. While the behavior of the Han Chinese was internally homogeneous, Tibetans demonstrated a higher probability of accepting offers per se, which remained largely unaffected by the amount offered. The authors ascribe this result to the cultural differences explained by Tibetans' religiousness.

In addition to differences in fairness concepts, the group context and location in which decisions are made influences the outcome and reflects the different levels of social orientation across cultures. For instance, Valenzuela et al. (2005) examine 
Table 2. Cross-cultural experimental studies based on Ultimatum Game (UG) applications (for a detailed description incl. game tree, see Appendix I)

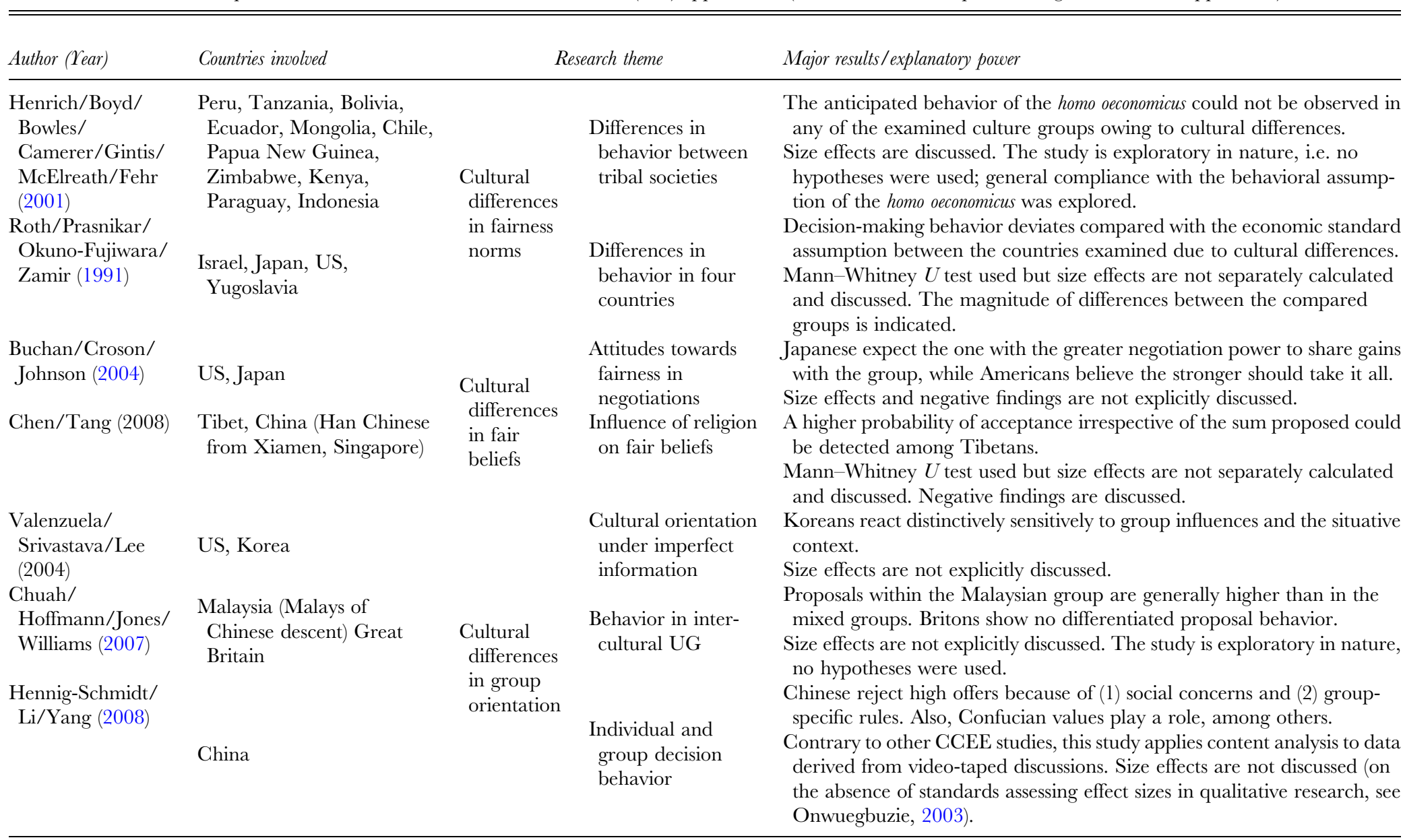


the effect of different cultural orientations by means of an UG with an incomplete distribution of information in the US and South Korea. In comparison to Americans, South Korean test persons show a distinct sensitivity to the influences of the group as well as to the situational context as soon as information about them was available. The authors assume that Korean participants are more likely to accept a relatively low offer when decisions are made that include the group context. In the US, however, no such effect is observed. Chuah et al. (2007, 2009) compare the decision-making behavior of participants from Malaysia and Great Britain by taking the decision-making location into account. Malay proposers and responders in Malaysia and British proposers and responders in Great Britain show significant differences in proposer behavior. The amount offered is generally higher in the Malay treatment group. Equally interesting is the result of the inter-cultural scenario. In this case, Malays generally offer lower amounts to the British but not to other Malays. The British, however, do not change their behavior. The results significantly testify that group homogeneity and location (country) affect bargaining behavior, i.e., when Malays played in Britain, their offers were higher.

\section{Cooperation and Sanctioning}

Representative studies that examine cultural factors in public good (PG) games (for a detailed description, see Appendix II) have been conducted by Weimann (1994), Burlando and Hey (1997), Cason, Saijo, and Yamato (2002), Castro (2008), Kocher, Cherry, Kroll, Netzer, and Sutter (2008), Herrmann, Thöni, and Gächter (2008), and Gächter and Herrmann (2009). Table 3 provides an overview of the studies analyzed.

Central to the public good game is the conventional rationality assumption of economic behavior that predicts that the contribution of every player equals zero regardless of the number of rounds played. In experiments, however, this assumption cannot be verified. Participants instead contribute approximately $50 \%$ of their lot during the first round, which, however, decreases with the number of rounds. No contribution is an exception (Weimann, 1994). Applying the public good game in a cross-cultural setting sheds more light on the test person's willingness to cooperate, the structure of interaction, and social behavior. Weimann (1994) explores whether the offer levels contributed during the game differ between strangers or partners. Subsequently, he refines Andreoni's (1988) study, which concludes that strangers generally contribute more, but that the contribution amounts of both strangers and partners drop to a minimum during the last round. Andreoni assumes that this may be the result of cooperative efforts to establish social norms, which, however, do not prevail. The declining amount is therefore an expression of capitulation. However, Weimann (1994) could not reproduce Andreoni's results in the sense that strangers always contribute more. Andreoni conducted the experiment with US students and Weimann with German students.

(C) 2018 The International Association for Chinese Management Research 
Table 3. Cross-cultural experimental studies based on Public Good (PG) game applications (for a detailed description incl. game tree, see Appendix II)

\begin{tabular}{|c|c|c|c|c|}
\hline Author (Year) & Countries involved & \multicolumn{2}{|c|}{ Research theme } & Major results/explanatory power \\
\hline Weimann $(1994)^{*}$ & \multicolumn{2}{|l|}{ Germany } & $\begin{array}{l}\text { Rational decision- } \\
\text { making behavior }\end{array}$ & $\begin{array}{l}\text { Americans act more rationally than Germans. } \\
\text { Size effects are not explicitly discussed. }\end{array}$ \\
\hline $\begin{array}{l}\text { Burlando/Hey } \\
(1997)^{*}\end{array}$ & \multicolumn{2}{|l|}{ Great Britain, Italy } & $\begin{array}{l}\text { Free-riding } \\
\text { behavior }\end{array}$ & $\begin{array}{l}\text { Anglo-Saxons tend to free-ride compared with Italians or Germans. } \\
\text { Size effects, null and negative findings are discussed. }\end{array}$ \\
\hline Castro (2008) & Italy, Great Britain & \multirow[t]{2}{*}{$\begin{array}{l}\text { Cooperation } \\
\text { behavior }\end{array}$} & $\begin{array}{l}\text { Cooperation and } \\
\text { group composition }\end{array}$ & $\begin{array}{l}\text { The proposed amounts were higher in homogeneous groups than in mixed } \\
\text { groups. } \\
\text { Size effects, null and negative findings are discussed. }\end{array}$ \\
\hline $\begin{array}{l}\text { Kocher/Cherry/ } \\
\text { Kroll/Netzer/ } \\
\text { Sutter (2008) }\end{array}$ & US, Austria, Japan & & $\begin{array}{l}\text { Conditional } \\
\text { cooperation }\end{array}$ & $\begin{array}{l}\text { The level of conditional cooperation (with respect to the willingness to } \\
\text { contribute to a PG when others contribute as well) is higher in the US } \\
\text { than in Austria and Japan. } \\
\text { Size effects are not explicitly discussed. }\end{array}$ \\
\hline $\begin{array}{l}\text { Cason/Saijo/ } \\
\text { Yamato (2002) }\end{array}$ & US, Japan & \multirow{3}{*}{$\begin{array}{l}\text { Sanctioning } \\
\text { behavior }\end{array}$} & $\begin{array}{l}\text { Nature of sanction- } \\
\text { ing behavior }\end{array}$ & $\begin{array}{l}\text { Japanese tend to sanction participants who contribute little to the PG. } \\
\text { Size effects, null and negative findings are discussed. }\end{array}$ \\
\hline $\begin{array}{l}\text { Gächter/ } \\
\text { Herrmann } \\
(2009)\end{array}$ & Russia, Switzerland & & $\begin{array}{l}\text { Reciprocity and } \\
\text { antisocial } \\
\text { sanctioning }\end{array}$ & $\begin{array}{l}\text { Culture has a strong influence on reciprocity. Antisocial punishment is } \\
\text { more prevalent than expected. } \\
\text { Size effects are not explicitly discussed. }\end{array}$ \\
\hline $\begin{array}{l}\text { Herrmann/ } \\
\text { Thöni/Gächter } \\
\text { (2008) }\end{array}$ & $\begin{array}{l}\text { US, Great Britain, } \\
\text { Denmark, Germany, } \\
\text { Switzerland, Belarus, } \\
\text { Ukraine, Russia, Greece, } \\
\text { Turkey, Saudi Arabia, } \\
\text { Oman, South Korea, } \\
\text { China and Austria }\end{array}$ & & $\begin{array}{l}\text { Cross-cultural anti- } \\
\text { social punishment }\end{array}$ & $\begin{array}{l}\text { The sanctioning of very small as well as very high contributions (antisocial } \\
\text { punishment) differs significantly. A connection between civil solidarity } \\
\text { and rule of law on the probability of antisocial punishment is assumed. } \\
\text { Size effects are not explicitly discussed. }\end{array}$ \\
\hline
\end{tabular}


Just as Andreoni assumes the possibility of cultural influences, Weimann interprets his finding such that American students act more rationally than German ones. Further, Burlando and Hey (1997) also repeat the Andreoni experiment using British and Italian subject pools. Their result concurs with Weimann's findings. Although the focus of their study adopts Weimann's assumption of cultural differences, Burlando and Hey (1997) specifically find that Anglo-Saxons tend to freeride compared with Italians: the tendency to free-ride shows a higher magnitude for British than for Italians.

Castro (2008) examines the cultural differences between Italian and British students using the PG game. Participants are divided into homogeneous and mixed groups. The result shows that British students contribute more to the public good than Italian students. From a cultural perspective, the conclusion of the study is interesting as it states that the contributions in the culturally homogeneous groups are higher than those in the mixed groups. Kocher et al. (2008) explore the extent of conditional cooperation in the US, Austria, and Japan. Conditional cooperation is understood as the will to contribute to a PG under the premise that others contribute as well. The authors conclude that both the frequency of cooperation and the relation between one's own contribution and those of other participants are significantly higher among US participants compared with the behavior observed in Austria and Japan. The latter finding implies that the inclination to contribute to a public good, if others contribute as well, is fairly high among American test persons. The higher the contributions of other actors, the higher are their own contributions.

The actions taken by actors to establish social norms can be examined as an aspect of cooperation behavior. The sanctioning of players is an opportunity to effect a change in behavior. Cason et al. (2002) explore spiteful behavior and cultural differences within the framework of a two-person PG game with US and Japanese test persons. Participants have, in a departure from the conventional modeling of a PG game, the opportunity to tell the other players if they will contribute to the PG or not before they make their decisions. Therefore, players are given the possibility of taking this information into account when making their own decisions. Spitefulness is understood as a sanctioning mechanism toward other members who only contribute very little to the PG. This manifest itself as comparably low contribution amounts among Japanese test persons as soon as it is known that one player will make no contribution. This behavior leads, among Japanese test persons, to a more efficient overall result. Whereas American participants contribute higher amounts in general, cooperation is lower when a player makes no contribution. As a result, the authors conclude that Japanese test persons tend toward spiteful behavior toward free-riders expressed by low contributions. Further, Gächter and Herrmann (2009) test participants from Switzerland and Russia. In groups of three, a one-shot PG game is played in two variants, namely one option that provides the opportunity to sanction and one that does not. No difference in sanctioning is observed within the context of the respective

(C) 2018 The International Association for Chinese Management Research 
group. However, both groups show significant differences: the sanctioning in the Russian group turns out to be more severe than that in the Swiss group. Not only is free-riding and the contribution of small amounts punished but so is the contribution of amounts that lay within the group average. The latter is described as antisocial reciprocity (punishment) and applies to the punishment of absolutely positive contributions. The authors suggest that the cultural determinants of negative reciprocity should be investigated further in order to examine why punishment also occurs with pro-social behavior.

By using an identical research design, Herrmann et al. (2008) play a PG game in 16 countries with the goal of examining differences in sanctioning behavior. The results again show strongly divergent patterns of behavior between the participants from the respective countries. Whereas in some countries, very low contributions are punished, higher-than-average contributions are punished in other countries. The authors term this form of behavior antisocial punishment. Antisocial punishment, observed in all countries, can be, according to the authors, a form of revenge or an instrument to force cooperation. The respective distinctions, however, can be a sign of culturally different personality traits such as the striving for dominance of a competitive personality, or the pursuit of maximum advantage. On the other hand, those who contributed little and who were punished by those who contributed a lot may feel exposed and thus punish them in return. A further explanation would be striving for normative equality, according to which all dissenters from the norm, whether due to very little or very high contributions, experience punishment.

\section{Corruption and Social Preferences}

Cross-cultural studies applying the trust game (TG, for a detailed description, see Appendix III) include Carpenter, Daniere, and Takahashi (2004), Buchan and Croson (2004), Buchan, Johnson, and Croson (2006), Bohnet, Greig, Herrmann, and Zeckhauser (2008), Cameron, Chaudhun, Erkal, and Gangadharan (2009), and Barr and Serra (2010). They can be further classified into studies that examine social preferences in combination with the attribution of trust and the cross-cultural analyses of corrupt behavior (Table 4).

Carpenter et al. (2004) examine the factors of trust and cooperation among urban slum inhabitants in Thailand and Vietnam. Their data indicate that culture plays a major role in the extent to which people trust others and cooperate. As a result, the authors assume that cooperation behavior is determined by demographic factors such as gender, education, age, and affiliation time within a culturally homogeneous group. Based on the early studies of Hall (1959), who concludes that in some cultures trust is more highly valued than binding contracts, Buchan and Croson (2004) compare the quality of trust in the US and China. In their study, they make use of a variant of a TG, namely an investment game (Berg, Dickhaut, \& McCabe, 1995). The peculiarity of trust is, at a general level, 
Table 4. Cross-cultural experimental studies based on Trust Game (TG) applications (for a detailed description incl. game tree, see Appendix III)

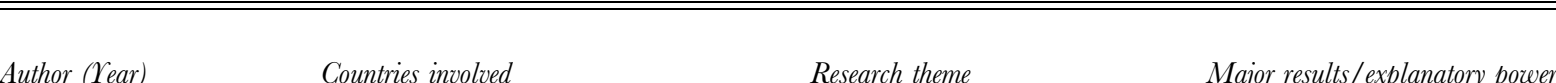

\section{Carpenter/Daniere/}

Takahashi (2004)

Thailand, Vietnam

Buchan/Croson (2004)

(Investment-game) ${ }^{* * * *}$

Buchan/Johnson/

Croson (2006)

(Investment game)***

Bohnet/Greig/

Herrmann/

Zeckhauser $(2007)^{* *}$

US, China

China, Korea,

Japan, US

Brazil, China,

Switzerland,

Turkey, UAE, US

\begin{tabular}{lll} 
Barr/Serra (2010) & 40 countries & $\begin{array}{l}\text { Corruption and } \\
\text { corruption } \\
\text { behavior }\end{array}$ \\
$\begin{array}{l}\text { Cameron/Chaudhuri/ } \\
\text { Erkal/Gangadharan } \\
(2009)\end{array}$ & $\begin{array}{l}\text { Australia, India, } \\
\text { Indonesia, } \\
\text { Singapore }\end{array}$ & \\
\hline
\end{tabular}

Cooperation behavior

Cooperation behavior within a culture group is determined by the

demographic equality of participants.

Size effects are not explicitly discussed.

Trust levels differ. The Chinese group showed a higher level of ingroup trust compared with the American group.

Size effects and negative findings are not explicitly discussed.

A 'country-of-origin effect' is identified, especially between US and

Chinese participants. Personal contact has a positive effect on deci-

sion-making. Individual cultural orientation also plays a role.

Size effects are not explicitly discussed.

Brazil: evidence of fraud aversion could not be identified. US/ UAE:

Fraud aversion

Susceptibility to

corruption

Tolerance towards corruption and costs

of corruption
Fraud aversion is especially distinct.

Size effects are discussed.

The willingness to be corrupt correlates with the spread of corruption in the native country but decreases if an individual integrates him- or herself into a less corrupt environment.

Size effects are not explicitly discussed.

Different levels of tolerance towards corruption are identified. The perception of the costs of corruption is culture-specific.

Size effects are not explicitly discussed.

Notes: ** In order to measure fraud aversion as well as risk behavior, a TG and a dictator game are adopted. *** The investment game is a variant of the TG. 
comparatively higher within the Chinese ingroup compared with the US one. However, at a more detailed level the results are rather heterogenic, leading Buchan and Croson to argue that 'the importance of trust (and trustworthiness) to economic relationships and growth suggests that the issue of national differences in trust and trustworthiness is one that we as economists need to better understand' (2004: 498).

Buchan et al. (2006) examine the influence of social distance and communication on trust and reciprocity using participants from China, Korea, Japan, and the US. After randomly selecting discussion groups, player pairs are composed with the goal of creating in- and outgroups. Some player pairs are composed of people who knew each other from the prior discussion (ingroup), while the other player pairs are composed of people who had no previous contact (outgroup). The authors testify that having previous personal contact leads to significantly higher trust ascriptions, even although no game strategies were agreed upon during the personal discussion. Contrary to the assumption that Chinese participants might show preferences toward their compatriots, they show more trust and reciprocity toward the outgroup, while American test persons show the contrary behavior. A survey conducted to analyze this result attests that Chinese participants have a high level of collectivistic attitude, while this does not especially differ among the other participants (those from the US, Japan, and Korea).

Bohnet et al. (2008) analyze the level of betrayal aversion by employing a TG, a decision game, and a dictator game with test persons from Brazil, China, Switzerland, Turkey, the United Arab Emirates (UAE), and the US. The study asks how far the level of betrayal aversion is influenced by another person (social risk) or by a higher force. The authors use a risk factor to embody the minimal probability of the acceptance of the test persons within a risk situation that can lead to the exposure of betrayal. Within the group of the Brazilian test persons, no signs of betrayal aversion could be detected, whereas this was especially distinct among the participants from the US and UAE. This finding can be attributed to the existence of specific (cultural) institutions in both countries that counteract fraudulent intentions and thus keep the material costs of betrayal rather low. In the US, this kind of betrayal-intention-minimizing institution is embodied by the legislative body, while in the UAE these institutions are mainly those influenced by Islamic culture as well as interpersonal relations.

Cameron et al. (2009) analyze cultural differences to examine tolerance toward corruption in Australia, India, Indonesia, and Singapore. The authors found that Indian participants show a higher tolerance toward corruption than participants from Australia. Contrary to expectations, participants from Singapore show a higher tolerance toward corruption and participants from Indonesia a far lower one. The perception of corruption costs thus seems to be culture-specific. By using an identical research design, Barr and Serra (2010) included a further stage in which a player has the choice to punish another 
player for the acceptance of a bribe. The game consists of three players who each play a one-shot game in three rounds. The first player represents a company representative who decides to offer a sum to a public official. He or she in turn can decide to accept or refuse the sum. The third player, who embodies a citizen, has the opportunity to punish him or her if he or she accepts the sum. Participants are recruited from 40 countries located either very low or very high on the Corruption Perception Index. The results of a repeat inquiry two years later led the authors to the finding that the inclination to behave corruptly correlated negatively with the duration of stay in Great Britain: the longer the students remained in Great Britain, the less they were inclined to act corruptly. Finally, the authors suggest that individual corrupt behavior can be regarded as a cultural phenomenon that is influenced by the environment.

\section{Norm Enforcement, Punishment, and Inequality Aversion}

Research designs that include more than one game application, mixed games (MG), allow for a broader perspective of analyzing decision-making behavior (Fehr \& Fischbacher, 2004). Although cross-cultural economic experiments using an MG approach are still rare, three remarkable studies are presented in the following that use an identical game mix that consists of an ultimatum game, dictator game, and third-party punishment game (for a detailed description, see Appendix IV). The dictator game can be regarded as a variant of the ultimatum game, whereby the feedback option is not given to the responder (see also Appendix $\mathrm{V})$. Only the proposer makes the decision about the share to be allocated to the receiver, which indicates the measure of fairness. Cultural differences were investigated in the framework of an MG design by Henrich et al. (2006), Barr et al. (2009), and Henrich, Hein, and Norenzayan (2010). These studies are summarized in Table 5.

Henrich et al. (2006) use a non-student subject pool that includes participants from 15 tribal populations from Africa, North and South America, Asia, and Oceania. Broadly formulated, the authors study cooperation behavior, specifically focusing on the (high-cost) punishment of other participants for unequal behavior. The results across the subject pools show that people are willing to exert costly punishment but that the willingness to punish differs across societies. Moreover, some communities punish very low offers as well as offers that are very high. In addition to these findings, the authors show that communities that have a high willingness to exert costly punishment also show more altruistic behavior. In a follow-up study, Henrich et al. (2010) investigate the evolution of fairness and punishment by using a partly overlapping subject pool from the survey in 2006. These findings can be regarded as an extension of those derived from the prior project. The authors find that the observed tribal communities, characterized by a small community size and low degree of market integration, show little motivation toward punishing unfair offers and are generally less concerned with fair behavior per

C 2018 The International Association for Chinese Management Research 
Table 5. Cross-cultural experimental studies based on Mixed Game (MG) applications (for a detailed description incl. game tree, see Appendix IV)

\begin{tabular}{|c|c|c|c|c|c|}
\hline Games included & Author (Year) & Countries involved & \multicolumn{2}{|c|}{ Research theme } & Major results/explanatory power \\
\hline \multirow[t]{3}{*}{$\begin{array}{l}\text { UG, third-party } \\
\text { punishment } \\
\text { game, dictator } \\
\text { game }\end{array}$} & $\begin{array}{l}\text { Henrich, McElreath, Barr, } \\
\text { Ensminger, Barrett, Bolyanatz, } \\
\text { Cardenas, Gurven, Gwako, } \\
\text { Henrich, Lesorogol, Marlowe, } \\
\text { Tracer, Ziker (2006) }\end{array}$ & $\begin{array}{l}15 \text { tribal populations from } \\
\text { Africa, North and South } \\
\text { America, Asia, and } \\
\text { Oceania (non-student } \\
\text { subject pool) }\end{array}$ & $\begin{array}{l}\text { Cooperation/ } \\
\text { norm } \\
\text { enforcement }\end{array}$ & $\begin{array}{l}\text { Costly punishment } \\
\text { (CP) among non- } \\
\text { student } \\
\text { populations }\end{array}$ & $\begin{array}{l}\text { Willingness to exert CP increases } \\
\text { according to unequal behavior but } \\
\text { the magnitude of CP differs across } \\
\text { populations. Altruistic behavior } \\
\text { and CP varies. } \\
\text { Size effects are discussed. }\end{array}$ \\
\hline & $\begin{array}{l}\text { Henrich, Ensminger, McElreath, } \\
\text { Barr, Barrett, Bolyanatz, } \\
\text { Cardenas, Gurven, Gwako, } \\
\text { Henrich, Lesorogol, Marlowe, } \\
\text { Tracer, Ziker }(2010 / 11)\end{array}$ & $\begin{array}{l}15 \text { tribal populations from } \\
\text { Africa, North and South } \\
\text { America, Asia, and } \\
\text { Oceania (non-student } \\
\text { subject pool)* }\end{array}$ & $\begin{array}{l}\text { Fairness/ } \\
\text { punishment }\end{array}$ & $\begin{array}{l}\text { The evolution of } \\
\text { fairness and } \\
\text { punishment }\end{array}$ & $\begin{array}{l}\text { Market integration influences fair- } \\
\text { ness, while community size influ- } \\
\text { ences punishment. } \\
\text { Size effects are discussed. }\end{array}$ \\
\hline & $\begin{array}{l}\text { Barr, Wallace, Ensminger, } \\
\text { Henrich, Barrett, Bolyanatz, } \\
\text { Cardenas, Gurven, Gwako, } \\
\text { Lesorogol, Marlowe, } \\
\text { McElreath, Tracer, Ziker (2009) }\end{array}$ & $\begin{array}{l}15 \text { populations from the } \\
\text { US, Amazon, Arctic, } \\
\text { Africa (student and non- } \\
\text { student subject pool) }\end{array}$ & $\begin{array}{l}\text { Fairness/ } \\
\text { inequality } \\
\text { aversion }\end{array}$ & $\begin{array}{l}\text { Do communities } \\
\text { differ in terms of } \\
\text { valuing equality? }\end{array}$ & $\begin{array}{l}\text { Differences across societies } \\
\text { observed in decision-making } \\
\text { behavior can be explained by a } \\
\text { different level of inequality } \\
\text { aversion. } \\
\text { Size effects are discussed. }\end{array}$ \\
\hline
\end{tabular}

Note: * Partly overlapping with Henrich et al. (2006). 
se. By comparison, the larger the observed communities are, the higher is the willingness to engage in punishment. Whereas in smaller societies kinship- and reciprocity-based norms prevail, Henrich et al. (2010b) summarize that the evolution of social norms in complex societies is influenced by those norms that ensure fair transactions.

Barr et al. (2009) inquire whether differences in inequality aversion can be explained by behavioral diversity. Participants in this study comprise students from the US and hunter-gatherer tribes from the Amazonia, the Arctic, and Africa. The authors apply an MG design in the fashion of that used by Henrich et al. $(2006,2010 b)$ in order to study the participants' appreciation of equality. In order to measure inequality aversion, a U-shaped utility function is used that considers the rejection of low offers (negative reciprocity) as well as the rejection of high offers. The authors find significant differences in decision-making behavior in all three games across all communities based on valuing equality; in other words, inequality aversion differs across countries. A universal attitude toward equality does not exist.

\section{New Trends - Moving Beyond National Gulture as a Proxy Variable}

By extending the definition of culture away from the sole country-culture view, the field of CGEE has recently progressed by going one step further and trying to unpack culture through focusing on (shared) values that may be responsible for behavioral differences, or by exploring the manifestation of social identity and discrimination when people from different cultures interact. In addition, several recent CCEE studies analyze ethnicity, race, and religion as proxies for crosscultural differences.

Diverging sets of values. Since approximately the second half of the first decade of the 2000s, cross-cultural experimental economists have moved on from merely recognizing behavioral differences between country-specific subject pools to trying to explain why these differences occur. One way to 'unpack' culture is by approaching it with a focus on values, as done by Chuah et al. (2009), who used an experimental approach in connection to attitudinal surveying in order to analyze bargaining behavior of Malaysian and British test persons. Dimensions of the World Values Survey were utilized in order to explain differences in attitudes, interpreted as cultural differences that may explain differences in decisionmaking behavior. Applying a bargaining game, the results showed that Malaysian proposers made higher offers to compatriots, but British proposers did not change their offer behavior based on responder nationality. While both groups differ in a variety of dimensions of the World Values Survey, it is interesting to note that the Malaysian test persons held more negative views toward outgroup members and were less in favor of expressing individual freedom and women's equal rights. Based on a regression analysis of the results, it is suggested that

(C) 2018 The International Association for Chinese Management Research 
attitudes rather than nationality are a more powerful predictor of behavioral differences.

By using a subject pool consisting of test persons from Finland, Lönnqvist, Walkowitz, Wichardt, Lindeman, and Verkasalo (2009) show that a person's conformism values are an antecedent of whether behavior is guided by an individual's values or by social norms. Three separate studies that the research includes come to the conclusion that conformism values moderate the influence of group norms on behavior. Further, in a group of people scoring low in conformism values, universalism values (Schwartz, Melech, Lehmann, Burgess, Harris, \& Owen, 2001) strongly predicted altruistic behavior.

Today, one stream of CCEE research progressed by focusing more on studying the influence of values on behavior by treating values as a proxy instead of national culture (see also Lönnqvist, Walkowitz, Verkasalo, \& Wichardt, 2011). A further advancement can be seen in the research stream on ethnicity, race, and religion as focus of research. The more countries become multicultural, the more difficult it is to think about culture only in the conventional dimensional categories. A more recent research stream treats, for instance, ethnicity, race, and religion as proxies for culture.

Ethnicity, race, and religion. Chuah et al. (2014) explore cross-ethnicity with test persons from Malaysia, a multicultural country composed of four main ethnic groups with differing languages and religious beliefs. The research design featured an experiment and a questionnaire to capture the subjects' demographics, ethnicity, religiosity, and fundamentalism. The study explores how the latter affect cooperation. Overall, ethnic and religious identity increases cooperation behavior; although religions identity increases it to a greater extent than ethnicity. Moreover, the sole knowledge of ethnic and religious differences does not influence cooperation, but the awareness of it increases cooperation. Also, a person's religiosity and fundamentalism do not influence cooperation. Further, the study finds that fundamentalism and religiosity can predict a higher level of ingroup favoritism, and fundamentalism predicts prejudice to outgroups and toward the ones who criticize religious doctrine (for a further study on ingroup favoritism, see, for instance, Fershtman, Gneezy, \& Verboven, 2005).

Using a trust game, Burns (2006) identifies a significant pattern of distrust of a Black partner, 'even by Black proposers' (Burns, 2006: 805), which occurs due to erroneous behavioral stereotypes. White proposers, on the contrary, more likely detract themselves from strategic interaction when paired with a Black partner.

Fershtman and Gneezy (2001) study ethnic discrimination in Israeli Jewish society. By using names as a proxy for the affiliation of the Jews to two different Jewish communities, they find that men in particular offer less to especially one of the two communities. Interestingly, the distrust toward the males of this community is perpetuated by the men themselves.

Studies on cross-religion within a country have been conducted, among others, by Johansson-Stenman, Mahmud, and Martinsson (2009, 2013) and 
Chuah, Fahoum, and Hoffmann (2013). Exploring trust ascriptions among Hindu and Muslim households in Bangladesh, Johansson-Stenman et al. (2009) find no evidence of social preferences or discrimination among both groups (for an extension to that study, see Johansson-Stenman et al., 2013). However, a survey conducted in addition to behavioral experiments reveals that both groups ascribe higher trust to their own respective religious groups. Further, Hindus exhibit lower levels of general trust, but they trust Muslims more than vice versa.

Whether India's societal fractionalization goes hand in hand with distrust between its main religious groups, i.e., Hindus and Muslims, is explored by Chuah et al. (2013). In fact, mutually lower offers between Hindus and Muslims tested in Mumbai reveal an intergroup bias and confirm the distrust between the groups. Contrary to the results of Johansson-Stenman et al. (2009), Chua et al. (2013) find that Hindus have greater trust, as well as greater expectations of others' trust.

Noteworthy are studies exploring cross-political systems within a country by focusing on solidarity behavior. Ockenfels and Weimann (1999) study solidarity behavior in East and West Germany and found, surprisingly, that Eastern Germans behave more selfishly than West Germans, despite the socialist legacy of East Germany. Interestingly, the experiment was repeated more than a decade later, but the result remained the same. Compared to West Germans, East Germans showed significantly less solidarity (Brosig-Koch, Helbach, Ockenfels, \& Weimann, 2011). The authors conclude that political values may change faster than social behavior.

Social identity and discrimination. Since the majority of industrialized countries have become more multicultural during the last two decades, experiencing an 'increase in ethnic and social heterogeneity' (Chen \& Mendel, 2016: 1), challenges of cultural heterogeneity within a country become important to understand in more detail. Hence, I have identified a further recent trend of CCEE research that focuses on social identity, which is shaped by culture and can lead to, e.g., discrimination when a person sharply distinguishes between in- and outgroup (for several studies dealing with these questions, see the recently published special issues edited by Chen and Mengel, 2016).

By focusing on trust and trustworthy behavior, Chuah, Gächter, Hoffmann, and Tan (2016) explore discrimination based on religious affiliation. By using test persons from China, Malaysia, and the UK, the authors find that similarity in religiosity and affiliation supports trust between partners, as it is believed that norms of reciprocity take effect. Further, religious test persons ascribe a higher level of trustworthiness to others of the same religious belief.

Chowdhury, Jeon, and Ramalingam (2016) explore the link between social identities and group conflict. Their research design features a setup consisting of two groups: White Caucasians (incl. test persons from North- and West Europe, the US, and Canada), and East Asians (incl. test persons from Japan, South Korea, China, Hong Kong, Macau, and Taiwan). Performing a group contest, 
in one setup, the racial composition of the group is not revealed, and in another, race information is disclosed. As a result, in the latter treatment, free-riding is observed to decline but conflict effort increases. This was not observed in the treatment in which race information was hidden. The studies presented in this section are summarized in Table 6.

\section{What about Gross-cultural Experimental Management?}

Despite the large variety of research methods, the discipline of management applies to study cross-cultural phenomena, 'experimentation is surprisingly underemphasized' (Leung \& Su, 2004: 68). This has been also observed in the field of International Business (IB) studies (Leung et al., 2005; van Witteloostuijn, 2015). However, that does not mean that there are zero cross-cultural experimental studies conducted in the management studies. The few studies that apply crosscultural experiments most often use country culture as a proxy variable but rarely go deeper (comp. Kirkman, Lowe, \& Gibson, 2006). Due to the low number of studies, it is currently difficult to clearly separate, categorize, and systematically summarize research in that field in the same fashion as I have done above for the field of CCEE. Nonetheless, by looking above and beyond disciplinary boarders, there are some scattered examples of relevant studies worth mentioning.

In the management studies, analog to the above review of the strategic games used in CGEE, country culture is often used as a proxy variable for studying cultural differences. For instance, Gelfand et al. (2002), in the frame of a multi-method approach, include a laboratory experiment in order to study fairness perceptions on negotiations in Japan and the United States. This study provides evidence that, in the United States, the self-serving biases of fairness are more pronounced than in Japan where 'the self is served by focusing on one's negative characteristics to "blend in" and maintain interdependence with others' (Gelfand et al., 2002: 833). Contrary, in the United States, standing out and being better than others is positively attributed. Consequentially, the results of the study point toward aspects of social context and country-specific internalized ideals that question the conventional view of rationality in negotiations; this is based on accumulated knowledge that has so far been largely based on research conducted by Western scholars.

An approach to studying cultural differences within a multi-ethnic society can be found in the study of Cox, Lobel, and McLeod (1991) using the example of the United States. In this study, it is assumed that bi-culturals (i.e., Asian-, Black-, and Hispanic Americans) behave more collectivistically and cooperatively than Anglo Americans, who are assumed to be more individualistic and competitive. Test persons were allocated to different groups consisting of an all Anglo group and an ethnically diverse group consisting of the bi-culturals. The results confirm the assumptions made and point toward the importance of the situational context in which decisions are made. Further it points toward the difficulty of clearly classifying multi-ethnic societies along the line of the, e.g., popular individualism- 
Table 6. Studies going beyond national culture as a proxy variable

\begin{tabular}{|c|c|c|c|}
\hline Author (Year) & $\begin{array}{l}\text { Country or } \\
\text { countries involved }\end{array}$ & $\begin{array}{l}\text { Cultural proxy explaining } \\
\text { observed behavioral } \\
\text { differences }\end{array}$ & Major results/explanatory power \\
\hline $\begin{array}{l}\text { Chuah et al. } \\
(2009)\end{array}$ & Malaysia, UK & Different sets of values & $\begin{array}{l}\text { Better than nationality, attitudes are a predictor for behavioral differences. } \\
\text { Size effects are not discussed but issues of multicollinearity are taken care of. }\end{array}$ \\
\hline $\begin{array}{l}\text { Lonnquist et al. } \\
\text { (2009)* }\end{array}$ & Finland & $\begin{array}{l}\text { Personal values, social } \\
\text { norms }\end{array}$ & $\begin{array}{l}\text { The individuals' conformism values are one determinant of whether behavior is guided by } \\
\text { personal values or by social norms (p. 525). } \\
\text { Size effects and negative findings are discussed. }\end{array}$ \\
\hline $\begin{array}{l}\text { Chuah et al. } \\
(2014)^{*}\end{array}$ & Malaysia & $\begin{array}{l}\text { Ethnicity, } \\
\text { religiousness }\end{array}$ & $\begin{array}{l}\text { Similarities in ethnicity and especially religiousness increases cooperation behavior; religiosity } \\
\text { and fundamentalism predict ingroup favoritism; fundamentalism predicts a higher level of } \\
\text { outgroup prejudice. } \\
\text { Size effects are not explicitly discussed. The study is rather explorative in nature and observed } \\
\text { behavioral pattern are discussed. }\end{array}$ \\
\hline Burns $(2006)^{*}$ & South Africa & Race & $\begin{array}{l}\text { Distrust toward Black partners occurs due to mistaken behavioral stereotypes; When paired } \\
\text { with a Black partner, White proposers likely do not engage in strategic interaction. } \\
\text { Size effects are not explicitly discussed. }\end{array}$ \\
\hline $\begin{array}{l}\text { Fershtman \& } \\
\text { Gneezy (2001) }\end{array}$ & Israel & Ethnic discrimination & $\begin{array}{l}\text { Among two different Jewish groups, one is particularly distrusted concerning the males; dis- } \\
\text { trust is perpetuated by the men themselves. } \\
\text { Size effects are not explicitly discussed. }\end{array}$ \\
\hline $\begin{array}{l}\text { Johansson- } \\
\text { Stenman et al. } \\
(2009)^{*}\end{array}$ & Bangladesh & Religion & $\begin{array}{l}\text { Experiments show no differences in trust between Muslims and Hindus but survey results } \\
\text { reveal higher trust for a person's own religious group; Hindus exhibit lower levels of general } \\
\text { trust but they trust Muslims more than vice versa. } \\
\text { Size effects are not explicitly discussed but null and negative findings are discussed. }\end{array}$ \\
\hline $\begin{array}{l}\text { Chuah et al. } \\
(2013)^{*}\end{array}$ & India & Religion & $\begin{array}{l}\text { Mistrust between urban Hindus and Muslims of Mumbai is found in an inter-ethnic trust } \\
\text { game field experiment. } \\
\text { Size effects are not explicitly discussed. }\end{array}$ \\
\hline $\begin{array}{l}\text { Ockenfels \& } \\
\text { Weimann (1999) }\end{array}$ & $\begin{array}{l}\text { Germany } \\
\text { (East-West) }\end{array}$ & Solidarity & $\begin{array}{l}\text { East Germans show significantly less solidarity compared to West Germans. } \\
\text { Size effects and null and negative findings are discussed. }\end{array}$ \\
\hline
\end{tabular}


Table 6. Continued

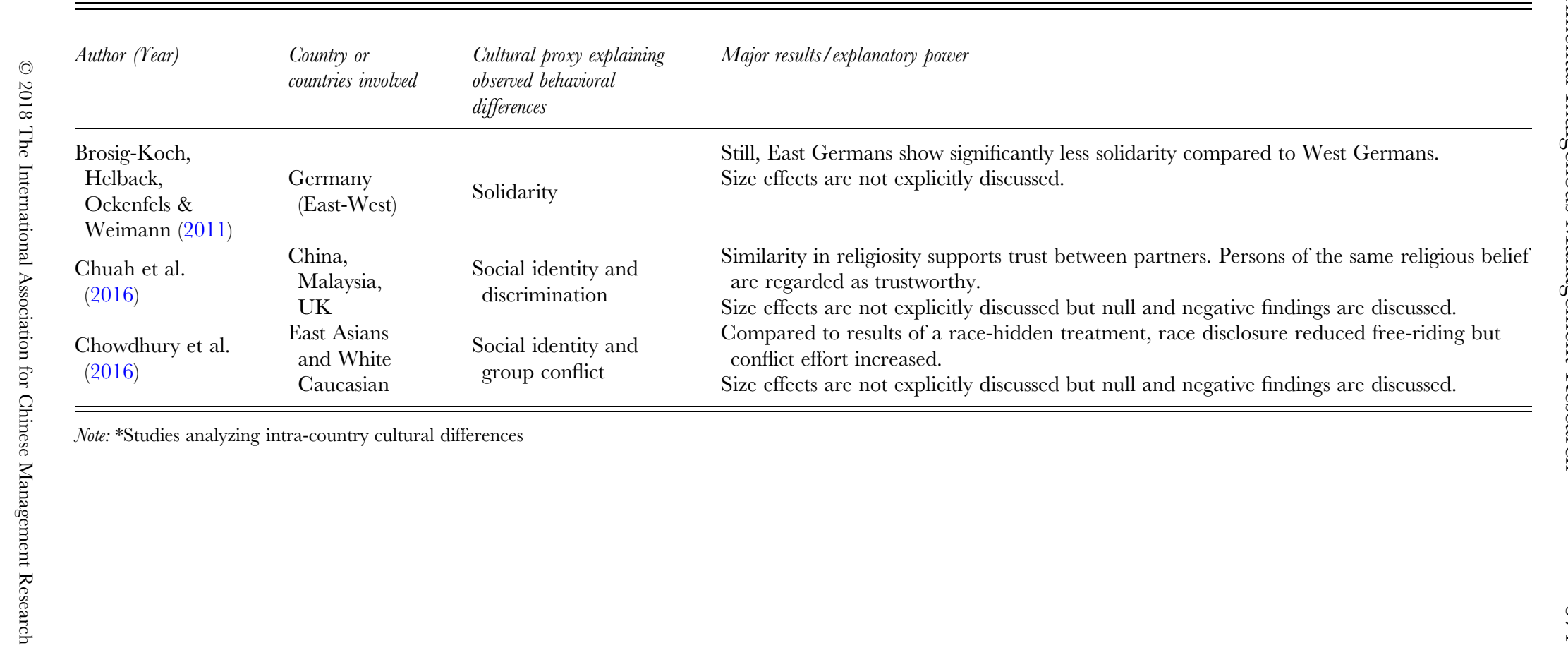


collectivism dichotomy, since situational context or group constellation trigger respective behavior. Chen and $\mathrm{Li}(2005)$ study cooperative decision-making behavior of Chinese and Australian test persons by applying two cross-national experiments. It was assumed that the Chinese test persons would behave less cooperatively than the Australians in a mixed-motive business situation and under the absence of formal and informal sanctions systems. Further, it was assumed that Chinese people abroad behave less cooperatively with foreigners than with fellow Chinese, while Australians would not make this distinction. As a result, the experimental data gathered support both assumptions. The study advances our understanding of the conventionally ad hoc assumptions drawn along the lines of dimensional models of culture as the 'cultural orientations of Australians and Chinese are more complicated than as suggested by previous findings from Hofstede' (Chen \& Li, 2005: 630).

In sum, it can be stated that there is a lack of approaches that go beyond the sole treatment of country culture as a proxy variable. Extant studies use country culture and rather broad or horizontal characteristics (e.g., individualism, collectivism, etc., comp. Jung \& Avolio, 1999, or Koch \& Koch, 2007) instead of verticalizing their approach and diving deeper into indigenous antecedents of a culture. Nevertheless, it is a positive development that past research directs attention to, e.g., social context and internalized ideals. However, so far, most research cannot clearly answer of what cultural tiles the social context is comprised and what ideals are in detail and whether and how they in fact influence behavior.

\section{LESSONS LEARNED AND THE MISSING LINK}

Echoing earlier implications of research that reflect the progressing decay of the behavioral assumptions of the homo oeconomicus (e.g., Boone, De Brabander, \& Van Witteloostuijn, 1999; Falk \& Fischbacher, 2006; Henrich, 2000; Henrich et al., 2001; Kahneman et al., 1986; Thaler, 1988), Stigliz noted in his Nobel prize speech that 'the economists' traditional model of the individual is too narrow' (Stiglitz, 2002: 488). While traditional economists have not given the influence of culture on decision-making behavior much thought (Jones, 2006), the implications derived from cross-cultural economic experiments are particularly interesting. They provide empirical evidence that the standard assumption of economic behavior (i.e., the homo oeconomicus) would need revision as culture de facto moderates economic behavior. Moreover, a consciousness of fairness in human transactions, a feature the homo oeconomicus does not care about, differs across countries, often in a way so that decisions even cause economic loses. The results from the experiments presented above grant deeper insights into how people from different cultures behave when urged to make critical decisions. If fair behavior and the norms of cooperative behavior deviate based on the prevailing social norms in a community, they are enforced with a different intensity (e.g., some studies found differences in the level of free-riding). Japanese tend to sanction free-riders more

(C) 2018 The International Association for Chinese Management Research 
strongly than Americans do and Russians punish overly egoistic as well as overly altruistic behavior much more strongly than the Swiss. Generalizations derived from these studies provide useful indications for further inquiry, for instance, how culture influences group decision making. It makes a difference whether a group consists of culturally homogeneous participants or whether decisions are made in heterogeneous groups. Here, some national cultures are affected by the group constellation, whereas others are not. Moreover, religion, an important cultural factor of influence, can also explain differences in decision-making behavior (Chen \& Tang, 2009).

Implications based on these results, however, have to be treated with caution. Given the absence of consistently applied standardized effect measures, past CGEE studies have rarely discussed size effects or negative or null results. Analog as to the challenges in conducting a meta-analysis in the psychology discipline (comp. Morris \& DeShon, 2002), CCEE studies often fail to provide enough information to sufficiently assess size effects or use different experimental designs to explore the same phenomena. Replicability gets complicated when different experimental designs estimate different population parameters (Glass, McGaw, \& Smith, 1981; Morris \& DeShon, 1997; Ray \& Shadish, 1996). Spending more attention on interpreting size effects as well as discussing negative or null results, would increase the quality of insights based on the results generated (Lewin et al., 2016).

However, despite all its achievements, CGEE has not yet exhausted all of its potential. Thought progress has been made since the 1990s when differences in decision-making behavior of test persons from different countries was assumed to be caused simply by cultural differences, to more recently when questions of behavioral differences were explored through a focus on ethnicity, individual values, or social identity, still one may argue that CCEE could dive deeper into questions that make us better understand the effect of culture on decisionmaking behavior. For instance, Oosterbeek et al. (2004) is missing a more detailed understanding about the 'underlying factors' of behavioral differences. Also CCEE needs 'to identify the components of particular cultural systems and the respective effects these have on economic behavior' (Chuah et al., 2007: 46). So how can indigenous management scholars bring in their competencies? The following section proposes how research can be designed in the future to integrate a higher degree of contextualization in order to study the influence of cultural factors on decision-making behavior in more depth.

\section{TOWARD EXPERIMENTAL INDIGENOUS MANAGEMENT RESEARGH}

\section{Suggestions for Future Research}

Just as the economic rise of many emerging countries has generated higher demand for explaining the reasons of their success (e.g., their management 
practices), awareness has grown among the scholarly community that conventional management theories, coined mostly by Western scholars' ideas, are not universal per se, or they are unable to fully explain the managerial principles of many emerging market economies (Van de Ven \& Jing, 2012; Werner, 2002; Zhao \& Jiang, 2009). The currently flourishing field of Indigenous Management Research (IMR) aims to better understand distinctive cultural factors and their influence on management (Leung, 2012; Li, Leung, Chen, \& Luo, 2012; Li, 2015; Tsui, 2007; Van de Ven \& Jing, 2012). By taking the cultural context explicitly into account, IMR aims to overcome the scientific paradigms developed predominately by Western scholars in the past (Banerjee \& Prasad, 2008; Barney \& Zhang, 2009; Fang, 2009; Lin, 2002; Tsui, 2004). Following the call for high-quality IMR (Tsui, 2004), this paper argues that an experimental methodology can make a contribution to IMR by drawing on the strengths of both IMR (i.e., contextualization) and CCEE (i.e., methodology). Typically, IMR uses comparative case analysis, participant observations, interviews, questionnaire-based surveys, or ethnographic inquiry (Fang, 2012; Ma, 2012; Van de Ven \& Jing, 2012; Wu, Huang, Li, \& Liu, 2012). Since experiments have not been popular in IMR as of yet, how can they help? Experimental approaches would well suit to drive, for instance, guanxi research to a next level (Chen, Chen, \& Huang, 2013; Li et al., 2012; Song, Cadsby, \& Bi, 2012). So far the bulk of research on guanxi has been either conceptual (Fan, 2002, 2007; Luo, 2008) or based on interviews (Anderson \& Lee, 2008; Zolkiewski \& Feng, 2012) or questionnaires (Yen, Barnes, \& Wang, 2011; Yi \& Ellis, 2000). An experimental research design would contribute to current knowledge by exploring how subjects behave in a close-to-reality environment as members of a guanxi network. Whereas currently, guanxi is often treated as an en bloc phenomenon, or an aggregate that actually consists of several antecedents, approaches are needed that test the effects of particular antecedents of the guanxi construct. Therewith, quantitative data could be generated that would add to the discourse of whether guanxi is still influential today or whether it is transforming or declining (Brennan \& Wilson, 2010; Guthrie, 1998; Lee \& Dawes, 2005).

By using the case of Korea, the study presented in the next section exemplifies an approach for how indigenous cultural context variables can be extracted, integrated, and tested in the frame of an experimental indigenous research design that leads to a better understanding of how and in what way they engender influence on actual behavior.

Example - Testing cultural context variables $(C C V)$. A showcase example of an experimental indigenous research design is the study on decision-making behavior and cultural context variables by Horak (2016). In order to understand the influence of distinctive cultural variables of the Korean cultural context on decisionmaking behavior, this study integrates high-impact cultural context variables into the research design. Thus, it responds to the call for a research design that leads to a better understanding of the underlying factors that influence decision

(C) 2018 The International Association for Chinese Management Research 
making. In this study, the 'primary objective is to investigate how cultural values embodied in the Korean cultural context influence the decision-making behavior (...)' (Horak, 2016: 282). The study features a two-stage design consisting of expert interviews in the first stage and behavioral field experiments in the second. The first stage serves to identify important variables of the cultural environment that influences decision making in Korea. The results of the interviews showed that a variety of factors play a role, with, among the most influential ones being seniority, as a crucial variable derived from the moral philosophy of Confucianism, which is pervasive throughout Korean society. Further, the interview partner reported that education-based ties (university and/or high school), regional origin, and family ties play an important role as these factors represent central elements of the social identity of Koreans. Going deeper, the interviews revealed that these three ties are commonly known as so-called yongo ties. The first syllable of this Korean term, 'yon', translates into 'tie' and the second syllabi 'go' carries the meaning that the tie exists for a reason, and the reason is usually a shared background composed of the same home town (i.e., regional origin, in Korean: juyon [지연]), attendance at the same high school and/or university (in Korean: hakyon [학연]), and blood ties (i.e., family ties, in Korean: hyulyon [혈연]). It can be stated that Korean society, especially the Korean business and political sphere, consists of pervasive informal ties based on exactly these yongo ties. Yongo ties usually last for life and their strengths depend on how intensively they are maintained. Yongo is characterized as immutable, and to some extent, predefined (i.e., given by birth) with education-based ties today being the exception, as they can be freely chosen.

As a result of the interviews, a set of selected variables, the cultural context variables $(\mathrm{CCV})$, were, in the second stage, integrated in an ultimatum game that was played in two variants. One variant featured the CGVs and the other, for benchmark reasons, the standard version of the ultimatum game. In the frame of a paper-and-pencil experiment, the CGVs were communicated in writing to the respective decision maker. By following the same protocol, these two games were played in Korea among a Korean subject pool as well as in Germany among a German subject pool. The latter represented a culturally different environment that was chosen for comparative reasons. It was assumed that if the $\mathrm{CGVs}$ represent distinctive Korean variables of the cultural environment they would influence the decision-making behavior of the Korean test persons but would not deploy influence among a German subject pool. Interestingly, these assumptions could be confirmed. In more detail, by distinguishing decision-making behavior among the sexes, it turned out that male Koreans very strongly responded to the GCVs. Depending on their randomly assigned position in the game, they either behaved egoistically in relation to their offer behavior or responded by not accepting even an advantageous offer. On the contrary, Korean females did not change their behavior independent of the game condition and respective randomly assigned role. Interestingly, a change of behavior could not 
be observed among the female and male test persons in Germany, where the CGVs had no influence.

The research approach taken in this study goes beyond the conventional country culture comparison and individualism-collectivism ad hoc interpretation by first identifying and extracting influential antecedents of the cultural context that may influence behavior. This approach represents a small step toward a better understanding of the components of a cultural system and opens up new avenues for future research by putting the identification and testing of specific high-impact $\mathrm{CGVs}$ of a respective cultural environment at the center of the approach.

\section{Prerequisites, Ghallenges, and a Process Model for Experimental Indigenous Management Research}

In order to conduct such research, a precondition is the possession of profound knowledge about the cultural environment and its specific context factors. Experimenters unfamiliar with the prevailing behavioral ideals of respective cultures need to be aware that a lack of knowledge of indigenous culture runs the risk of testing behavioral dimensions that are influenced by prevailing behavioral norms without knowing them. As a result, data may easily be misinterpreted. Close research cooperation with local scholars familiar with the environment hedges this risk (Tsui, 2007; Van de Ven \& Jing, 2012; Zhao \& Jiang, 2009).

Alternatively, once behavioral differences are indentified across cultural lines, applying a multi-method design may help, for example, by conducting contextualized qualitative research using ethnographic research methods or narrative interviews in order to identify high-impact context variables. In a further step, the identified context variable(s) could be integrated into an experimental research design and tested in the field, as proposed in the study by Horak (2016) presented above (Figure 1).

In order to increase validity, a triangulation of data could be conducted by including a third stage after the experiment: a post-experimental questionnaire or a post-experimental interview (e.g., Greiner, Caravella, \& Roth, 2014; Lönnqvist, Verkasalo, Walkowitz, \& Wichardt, 2015; Maciejovsky, Kirchler, \& Schwarzenberger, 2007). Both instruments serve to gain a better understanding of the motives and inferences of particular decisions by the test persons. In terms of indigenous research on East Asia, for instance, when certain antecedents of seniority are explored, the filial piety scale (Ho, 1996; Ho \& Lee, 1974) could be administered after the experiment. Depending on the nature of the research subject, the experimentor needs to decide whether a post-experimental questionnaire or a postexperimental interview suits better. This decision is, in principle, similar as the decision made before the experiments when the appropriate (pre-) interview instrument needs to be selected, for instance, narrative, semi-structured, or structured. While the nature of the research subject as well as the contextual knowledge

(C) 2018 The International Association for Chinese Management Research 


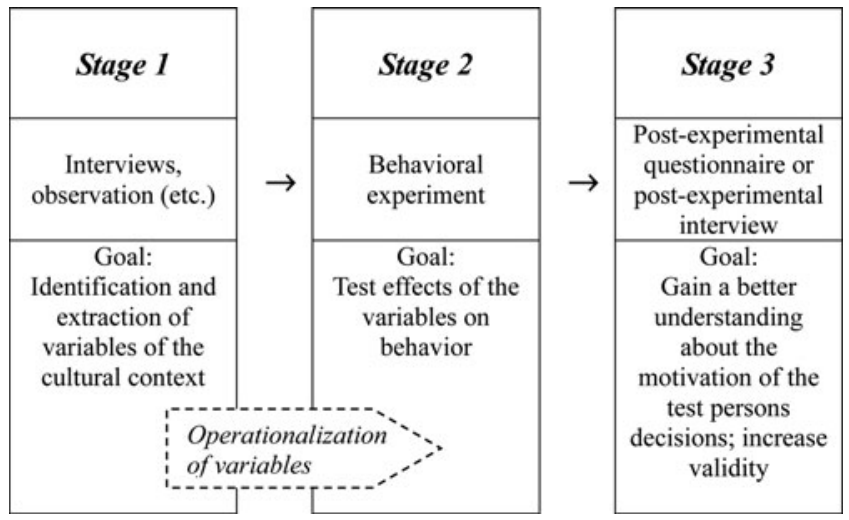

Figure 1. Proposal of a process model for experimental indigenous management research

level of the research will determine the decision, it may be suggested that a very novel theme and a rather low level of indigenous context knowledge would rather point toward the selection of narrative interviews, whereas for follow-up studies that are building on an existing body of knowledge, a questionnairebased post-experimental survey may be suitable. It remains an individual caseby-case decision. Taken together, these suggestions form a process model of experimental indigenous management research consisting of three stages, starting with the identification of variables of the cultural context (stage 1) and then proceed with applications to be aimed at testing and understanding the effects of the respective variables on behavior (stage 2 and 3). The proposed process model is shown in Figure 1.

The approach proposed would enable the determination in greater detail of the circumstances under which culture is and is not influential. The resulting findings can contribute to existing knowledge, for example, in the area of cooperation behavior in individualistic and collectivistic culture groups. It can also contribute to a better understanding of what determines the establishment of trust and trustworthiness across and between cultures, how fairness is interpreted across cultures, and how it is enforced. These questions can be answered by integrating contextspecific variables into the research design.

Another approach for achieving progress in better understanding culture is to investigate deeper the enduring paradigm of cultural dimensions. Experimental economic approaches can contribute to this field. In the past, concerns have been raised that conventional cultural categories (Hofstede, 1980, 1991) are not sufficiently suitable for explaining national cultures in a satisfactory way, and that they treat national cultures as static constructs (Fang, 2012; Van de Ven \& Jing, 2012). For instance, Japanese society is generally viewed as highly collectivistic (Hofstede, 1991) in which collective ingroup norms prevail and guide individual behavior. However, empirical research from the discipline of social psychology suggests that this claim should be treated with caution. Most Japanese people regard themselves as individualistic rather than collectivistic, but think that other 
Japanese people internalize collectivistic norms (Hirai, 2000). If collectivistic behavior helps secure resources, incentives are provided to act in such a manner. In that case, collective behavior is rather strategic, but is not based on internalized norms of collectivism as the conventional cross-cultural management literature indicates. Yamagishi, Hashimoto, and Schug (2008) suggest that the nature of Japanese collectivism has evolved through 'pluralistic ignorance'. Empirical evidence for this argument is provided by Ohbuchi and Saito (2007), who find that the maintenance of conflict avoidance behavior in Japan is a self-fulfilling prophesy. Other studies provide empirical evidence that Japanese collectivism should in fact be regarded as an individualistic strategy rather than an internalized, norm-based one (Yamagishi, Jin, \& Kiyonari, 1999; Yamagishi, Terai, Kiyonari, Mifune, \& Kanazawa, 2007). These are important findings toward a more grounded understanding of culture based on a deeply contextualized experimental approach.

\section{IMR and GGEE - Meeting in the Middle}

Economic experiments identify the behavioral differences derived from cultural differences but seldom provide an explanation based on cultural heritage in the form of the indigenous independent variables included in the research design. As a result, various studies lack detail and background concerning the factors from which cultural differences can be derived. On the other hand, IMR seldom uses experimentation in order to test independent variables typical for the country being studied. There is a great possibility that both disciplines may 'meet in the middle'.

Leung et al. (2005) see the advantages of the experimental methodology, especially in its ability to examine the causality of individual and group behavior (see also van Witteloostuijn, 2015). Therefore, it is possible to determine in greater detail the circumstances under which culture is and is not influential. The resulting findings can contribute to the advancement of management theory, for example, in the area of cooperation behavior in individualistic and collectivistic culture groups. It can also contribute to a better understanding of what determines the establishment of trust and trustworthiness across and between cultures, and how fairness is interpreted across cultures and how it is enforced. These questions can be answered by integrating context-specific variables into the research design. This proposal is in line with the recent call in economics to better understand the specific contextual variables that explain culturally-induced differences in decision-making behavior (Chuah et al., 2009; Oosterbeek et al., 2004). A key strength of economic experiments compared with other methodologies is that they allow researchers to observe closer to realworld behavior or 'attitudes in action' since they are incentivized by monetary benefits in a controlled environment (e.g., in an experimental lab) in which influencing factors can be controlled. 
The advantage that experiments can be designed in a way so that they can be replicated by other scholars contributes to attempts to replicate findings, which again adds to a better understanding about the consistency of the findings as well as size effects. Overall, I note that although many studies discuss null and negative findings at times comprehensively, studies discussing effect sizes explicitly and in detail are rare. This can possibly be explained by the absence of a common standard in the field of CCEE, which is especially the case for qualitative studies using content analysis (comp. Onwuegbuzie, 2003). The interpretation of different levels of variance would be especially important for an experimental approach to IMR in order to gain better insights into the meaningfulness of a statistical effect. In more detail, the interpretation of the effect size is important in order to understand better how strong, for instance, a cultural variable (independent variable) affects the dependent variable. Depending on the case, even small effects shouldn't be automatically labeled and interpreted as weak or trivial per se, since they can still represent impressive support for an examined phenomenon (Cortina \& Landis, 2009). In addition, in order to understand better the practical relevance of its inquiry (see also Aguinis, Werner, Abbott, Angert, Park, \& Kohlhausen, 2010), future research designs can apply complementary pre- or post-experimental interviews in order to better access practical implications of the respective themes explored.

\section{Subject Pool Selection and Incentive Compatibility}

What the right subject pool may be for what particular research question has been debated in the field of experimental economics (e.g., Alevy, Haigh, \& List, 2009; Croson \& Donohue, 2006) as well as in International Business studies (e.g., Bello, Leung, Radebaugh, Tung, \& Van Witteloostuijn, 2009). While it appears to remain essentially a case-by-case decision, in general, it can be recommended that the selection of an appropriate subject pool should be aligned with the respective research question. Whereas for very basic oriented research that aims to explore fundamental patterns of human behavior, a subject pool consisting of next to adults - young test persons (i.e., students) may be a valid option. However, by drawing on Sears (1986), Bello et al. (2009) recommend not using undergraduate students in particular, as they may likely have 'less crystallized attitudes, less-formulated senses of self, stronger cognitive skills, stronger tendencies to comply with authority, and more unstable peer group relationships' (Sears, 1986: 515). More clearly, when it comes to the study of proximate issues that focus more on a specific (practical) context, students with no real-world managerial experience would have difficulties responding to strategic decisions in a multifaceted international context. For this case, there is hardly a viable alternative to a subject pool of managers. Executive MBA students 'who are involved in high-level decision making could be appropriate, however' (Bello et al., 2009: 362).

Questions of subject pool compositions lead to questions of incentive compatibility. Finding a suitable level of incentives for a demographically similar group is 
crucial, as large deviations (i.e., overpay as well as underpay) may bias decisionmaking behavior. A suitable level of reward for student subjects is generally seen in the hourly compensation rate that a university would pay for a student assistant (Hennig-Schmidt et al., 2008). Rewarding management includes at least three major challenges. Gaining access to a larger group of this naturally busy type of test persons is one of them. Further, while it can be debated whether monetary incentives represent a suitable instrument to motivate a generally well-paid group of people, finding a suitable level of rewards is difficult, and as that level will very likely be much higher compared to that of students, larger research budgets are required, which may be a burden to acquire for the average scholar. As these potential constraints need to be taken into account before preparing a research project, there are, however, examples where scholars successfully solved the issue of budget constraints and gained access to a large number of CEOs willing to participate in a behavioral experiment, such as the study by Opper, Nee, and Holm (2017). In a recent AMJ (Academy of Management fournal) article, using a behavioral experiment, Opper et al., (2017) study risk aversion of Chinese CEOs by focusing on the association between risk aversion and the reliance on social relationships. The subject pool consists of $345 \mathrm{CEOs}$ of private manufacturing companies. Whereas on average the CEOs earned USD 47 each (in local currency: CNY 289), the maximum they were able to earn in the experiment was ca. USD 95 (corresponding to GNY 580 in local currency). In terms of the suitability of the level of the reward for CEOs in China, the authors believe that 'given the modest amount of time needed for completion [of the experiments] - [the reward] presented a credible incentive even for CEOs' (Opper et al., 2017: 1512).

In sum, scholars need to think critically about what subject pool may best suit the respective research questions. Once fundamental behavioral phenomena are explored, next to adults, graduate or MBA students might be a suitable option (Bello et al., 2009). In case questions relevant to a business setting are explored that target clearly a managerial context and aim at generalizing managerial behavior, undergraduate students very likely represent an unsuitable group of test persons, and managers would need to be recruited. Executive MBA students, as recommended by Bello et al. (2009), depending on the research context, may represent an alternative.

\section{GONGLUSION}

As several cross-cultural economic experiments (CCEEs) provide evidence that culture may moderate economic behavior, explaining why behavior differs has so far remained a challenge. Recently, the need to better understand the distinct nature (or underlying factors) that cause culturally-induced behavioral differences has been raised in experimental economics (Chuah et al., 2007; Oosterbeek et al., 2004). Whereas CCEE is, methodology-wise, fixed to behavioral experiments, indigenous management research (IMR) includes a large variety of qualitative

(C) 2018 The International Association for Chinese Management Research 
and quantitative research methods, except experiments. Following the call by Tsui (2004) for advancing indigenous research, in this paper I argue that an experimental methodology can advance IMR by combining the strengths of both approaches. In simpler terms, it is suggested that by pursuing an experimental indigenous research approach, distinctive cultural characteristics can be extracted in a first step, and then in a second step integrated into a controlled behavioral experiment in order to test their effects on behavior. A third stage can be implemented by conducting either post-experimental interviews or using a post-experimental questionnaire in order to support validity.

\section{APPENDIX I}

\section{Decision Options and Corresponding Results in a Standard Ultimatum Game (UG)}

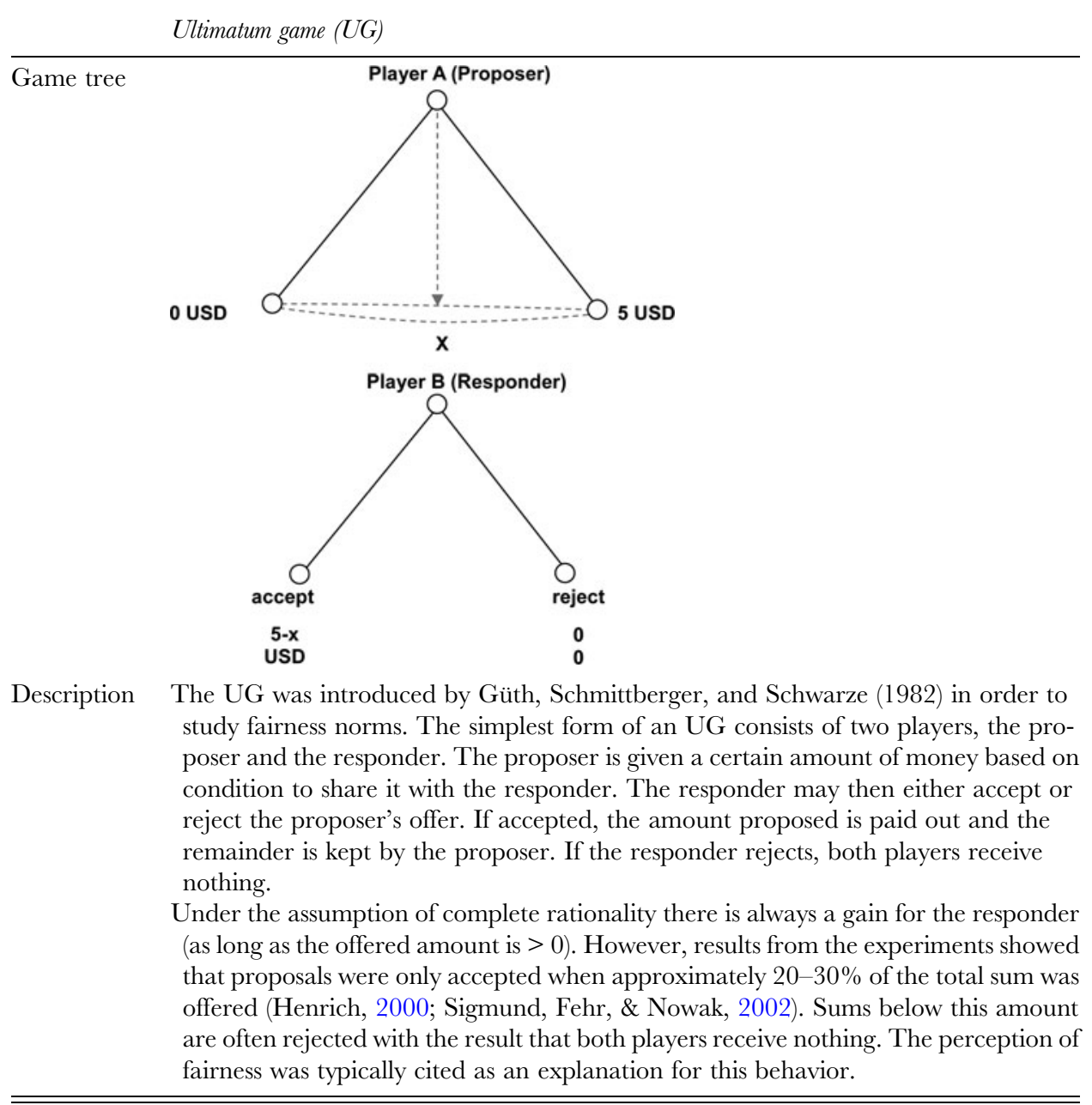




\section{APPENDIX II}

Decision options and corresponding results in a standard public good game $(\mathbf{P G})$

Public good game (PG)

Game tree

Player A

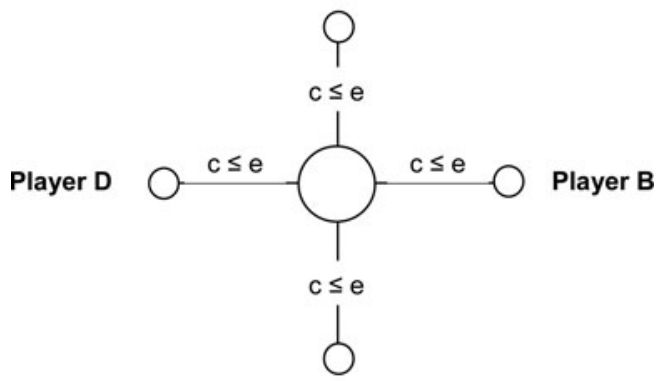

Player C

Note

$\mathrm{c}=$ contribution of player $n, \mathrm{e}=$ monetary unit from the capital available

Description Each participant is given a certain amount of money $(e)$ and each member can put a positive amount of $\mathrm{c} \leq \mathrm{e}$ into a common pot.

The experimenter multiplies the money in the pot by a constant $\delta>1$, which afterwards will be shared equally between the players, independent of the amount of money each has contributed. The share each player receives is:

$$
\delta / \mathrm{n}\left(\mathrm{c}_{\mathrm{i}}+\bullet \sum_{\mathrm{j}=1}^{\mathrm{n}=1} \mathrm{c}_{\mathrm{j}}\right)=\alpha_{i}
$$

The payoff function of each player $i$ is:

$$
\begin{aligned}
\pi_{\mathrm{i}} & =\left(e-c_{i}\right)+\delta / n\left(c_{i} \sum_{\mathrm{j}=1}^{\mathrm{n}=1} \mathrm{c}_{\mathrm{j}}\right) \\
& =\left(\mathrm{e}-\mathrm{c}_{\mathrm{i}}\right)+\alpha_{\mathrm{i}}
\end{aligned}
$$

If player $i$ contributes to the pot, then she will receive $\left(e-c_{i}\right)+\alpha_{i}$. If player $i$ does not contribute to the pot, then her payoff will be $e+\alpha_{i}$. If all other players $j$ do not contribute either, then each player receives e. Based on the conditions outlined above the optimal strategy would be for all players to contribute their whole endowments e. Then their payoffs will be exactly $\delta$ times their original endowment (that is $\delta \mathrm{e}$ ). 


\section{APPENDIX III}

Decision Options and Corresponding Results in a Standard Trust Game (TG)

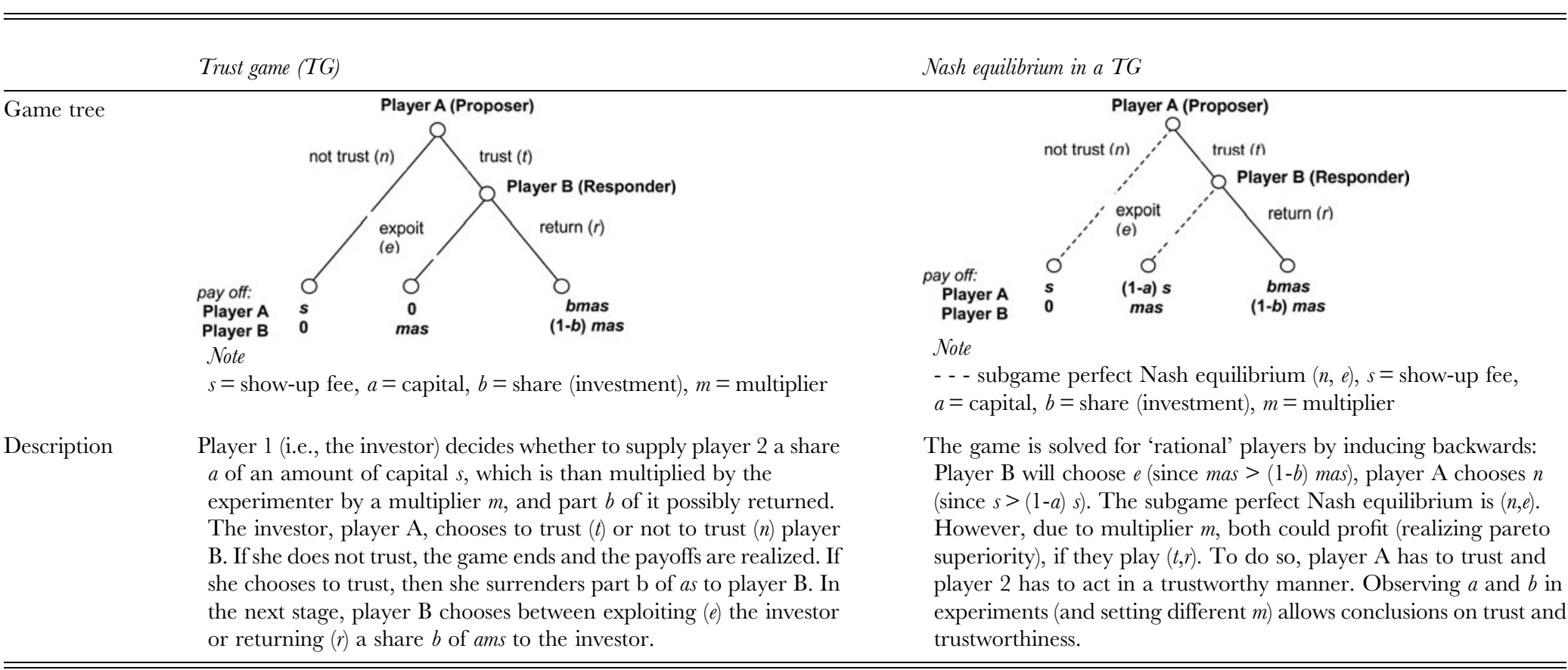
petting different $m$ ) allows conclusions on trust and 


\section{Appendix IV}

Third-party Punishment Game (3PPG) - Payoffs of Three Player (a) with Punishment and (b) without Punishment (Wxample)

(a) with punishment

\begin{tabular}{|c|c|c|}
\hline $\begin{array}{c}\text { Player 1 } \\
\text { (proposer, initial } \\
\text { endowment USD 10) }\end{array}$ & punish & $\begin{array}{c}\text { Player } 3 \\
\text { (third party, initial } \\
\text { endowment USD 5) }\end{array}$ \\
\hline $\begin{array}{l}\text { payoff:USD } 6 \\
\text { (USD 10-1-3) }\end{array}$ & & $\begin{array}{c}\text { payoff:USD } 4 \\
\text { (USD 5-1) }\end{array}$ \\
\hline
\end{tabular}

transfer decision: USD 1

\begin{tabular}{|c|}
\hline \multicolumn{1}{|c|}{$\downarrow$} \\
\hline $\begin{array}{c}\text { Player 2 } \\
\text { (responder) }\end{array}$ \\
\hline payoff:USD 1
\end{tabular}

(b) without punishment

\begin{tabular}{|c|c|c|}
\hline $\begin{array}{c}\text { Player 1 } \\
\text { (proposer, initial } \\
\text { endowment USD 10) }\end{array}$ & not punish & $\begin{array}{c}\text { Player 3 } \\
\text { (third party, initial } \\
\text { endowment USD 5) }\end{array}$ \\
\hline $\begin{array}{c}\text { payoff:USD 9 } \\
\text { pend }\end{array}$ & & payoff:USD 5 \\
\hline
\end{tabular}

transfer decision: USD 1

\begin{tabular}{|c|}
\multicolumn{1}{|c|}{$\begin{array}{c}\text { Player 2 } \\
\text { (responder) }\end{array}$} \\
\hline \\
\hline payoff:USD 1 \\
\hline
\end{tabular}

Description The 3PPG can be considered a design extension of a DG by including a third player, who is given the option of punishing the decision of the proposer in a DG setting. For example, the third player is given an initial endowment of $50 \%$ of the amount the proposer is endowed with. However, punishing the proposer is costly for the third party, e.g., $20 \%$ of his or her endowment. Moreover, if the third party decides to punish the proposer, a triple of the amount proposed to the responder is deducted from the proposers' endowment. E.g.: Player 1 (proposer) has a USD 10 stake to share with player 2 (responder); player 3 (third-party) has a USD 5 endowment. Now player 1 decides to keep USD 9 and transfer USD 1 to player 2. Player 3 can decide whether to punish the decision of player 1 or not.* If player 3 decides to punish, player 1's payoff is USD 6 (i.e., USD 10-1-3), player 2's payoff is USD 1 and the third parties' payoff is USD 4 (USD 5-1). Assuming money-maximizing intentions of player 1 and 3, player 1 would always transfer zero to player 2 and player 3 would never punish player 1.

Note: *Some designs provide the punishment option before player 3 becomes to know player 1's decision (Henrich et al., 2010/11), some designs afterwards (Fehr \& Fischbacher, 2004). 


\section{APPENDIX V}

\section{Other Common Game Applications}

Game Description

Dictator The Dictator Game (DG) is similar to the Ultimatum Game but it doesn't allow the game responder to respond. In the DG there are two players, and the dictator is given a certain sum of money to share with the responder. The dictator can decide to offer any sum ranging from zero to the full amount of the sum given. The responder must accept any sum that his offered. There is no option to reject the sum or punish the dictator. Conventionally the DG is used to study motivational aspects of offer behavior such as fairness or social preferences (Hoffman, McCabe, \& Smith, 2008).

\section{Example:}

Gong, B., Yan, H., \& Yang, C. L. 2015. Gender differences in the dictator experiment: Evidence from the matrilineal Mosuo and the patriarchal Yi. Experimental Economics, 18(2): 302-313.

Gift By applying the gift exchange, game aspects for reciprocity and fairness are studied.

exchange While there are different variants of the game, the conventional gift exchange game is a two player game, whereby one player is usually the firm and the other the employee; the game consists of two stages. In the first stage the firm offers its employee a wage; in the second stage the employee can either accept or reject that offer. If the latter rejects, the game ends without a payoff for either of the two parties. If the employee accepts, she makes a costly effort decision and is required to choose an effort level, whereby the higher the effort level is, the higher are the related effort costs. As for the payoffs, an increase in wages results in higher monetary payoffs for the employee but yields lower payoffs for the firm, while higher efforts have the reverse effect on payoffs.

Anticipating that employees will choose the lowest possible efforts, the firm will offer the lowest possible wage only (Fehr et al., 1993).

\section{Example:}

Gaechter, S., \& Falk, A. 2002. Reputation and reciprocity: Consequences for the labour relation. The Scandinavian Fournal of Economics, 104(1): 1-26.

Prisoner's With the prisoner's dilemma game, self-interest and cooperation behavior can be dilemma studied by offering two decision options: either to defect or to cooperate. The usual set up is as follows. There are two people put in jail for a crime. Both are not able to communicate with each other. The prosecutors, however, do not have enough evidence to convict the two on the principal charge. They hope to get both sentenced but on a lesser charge, and offer them a bargain accordingly at the same time. The two in prison are given the chance to either testify solely that the other is guilty (i.e., betray), or remain silent and cooperate with the other. Usually the following options are offered. First, if both betray each other, they both go to prison for two years. Second, if only one betrays the other and the other remains silent, the betrayer will be freed and the betrayed will go to prison for three years. Third, if both remain silent, they will only serve one year in prison (Axelrod \& Hamilton, 1981).

\section{Example:}

Andreoni, J., \& Miller, J. H. 1993. Rational cooperation in the finitely repeated prisoner's dilemma: Experimental evidence. The Economic Fournal, 103(418): 570-585. 


\section{REFERENCES}

Aguinis, H., Werner, S., Abbott, J. L., Angert, C., Park, J. H., \& Kohlhausen, D. 2010. Customercentric science: Reporting significant research results of rigor, relevance, and practical impact in mind. Organizational Research Methods, 13(3): 515-539.

Alevy, J. E., Haigh, M. S., \& List, J. A. 2009. Information cascades: Evidence from a field experiment with financial market professionals. Journal of Finance, 62(1): 151-180.

Anderson, A. R., \& Lee, E. Y. 2008. From tradition to modern: Attitudes and applications of guanxi in Chinese entrepreneurship. Journal of Small Business and Enterprise Development, 15 (4): 775-787.

Andreoni, J. 1988. Why free ride? Strategies and learning in public good experiments. Journal of Public Economics, 37(3): 291-304.

Andreoni, J., \& Miller, J. H. 1993. Rational cooperation in the finitely repeated prisoner's dilemma: Experimental evidence. The Economic Joumal, 103(418): 570-585.

Axelrod, R., \& Hamilton, W. D. 1981. The evolution of cooperation. Science, 21 1(4489): 13901396.

Banerjee, S. B., \& Prasad, A. 2008. Introduction to the special issue on 'Critical reflections on management and organizations: A postcolonial perspective'. Critical Perspectives on International Business, 4(2/3): 90-98.

Barney, J. B., \& Zhang, S. 2009. The future of Chinese management research: A theory of Chinese management versus a Chinese theory of management. Management and Organization Review, 5(1): 15-28.

Barr, A., \& Serra, D. 2010. Corruption and culture: An experimental analysis. Journal of Public Economics, 94(11-12): 862-869.

Barr, A., Wallace, C., Ensminger, J., Henrich, J., Barrett, C., Bolyanatz, A., Cardenas, J. C., Gurven, M., Gwako, E., Lesorogol, C., Marlowe, F., McElreath, R., Tracer, D., \& Ziker, J. 2009. Homo Aqualis: A cross-society experimental analysis of three bargaining games. Documento CEDE No. 2009-09. Available at SSRN: https://ssrn.com/ abstract $=1485862$, doi: $10.2139 /$ ssrn. 1485862

Bello, D., Leung, K., Radebaugh, L., Tung, R. L., \& Van Witteloostuijn, A. 2009. From the editors: Student samples in international business research. Journal of International Business Studies, 40(3): 361-364.

Berg, J., Dickhaut, J., \& McCabe, K. 1995. Trust, reciprocity, and social history. Games and Economic Behavior, 10(1): 122-142.

Binmore, K., \& Shaked, A. 2010. Experimental economics: Where next? Journal of Economic Behavior \& Organization, 73(1): 87-100.

Bohnet, I., Greig, F., Herrmann, B., \& Zeckhauser, R. 2008. Betrayal aversion: Evidence from Brazil, China, Oman, Switzerland, Turkey, and the United States. American Economic Revieze, 98(1): 294-310.

Boone, C., De Brabander, B., \& Van Witteloostuijn, A. 1999. The impact of personality on behavior in five Prisoner's Dilemma games. Journal of Economic Psychology, 20(3): 343-377.

Bowles, S., \& Gintis, H. 2002. Behavioural science: Homo reciprocans. Nature, 415(6868): $125-128$.

Brennan, R., \& Wilson, J. 2010. Doing business in China: Is the importance of guanxi diminishing? European Business Revieze, 22(6): 652-665.

Brosig-Koch, J., Helbach, C., Ockenfels, A., \& Weimann, J. 2011. Still different after all these years: Solidarity behavior in East and West Germany. Journal of Public Economics, 95(1 1): 13731376.

Buchan, N. R., \& Croson, R. T. A. 2004. The boundaries of trust: Own and others? Actions in the US and China. Joumal of Economic Behavior \& Organization, 55(4): 485-504.

Buchan, N. R., Groson, R. T. A., \& Johnson, E. J. 2004. When do fair beliefs influence bargaining behavior? Experimental bargaining in Japan and the United States. Journal of Consumer Research, 31(1): 181-190.

Buchan, N. R., Johnson, E. J., \& Croson, R. T. A. 2006. Let's get personal: An international examination of the influence of communication, culture and social distance on other regarding preferences. Journal of Economic Behavior \& Organization, 60(3): 373-398.

Burlando, R., \& Hey, J. D. 1997. Do Anglo-Saxons free-ride more? Journal of Public Economics, 64(1): 41-60.

Burns, J. 2006. Racial stereotypes, stigma and trust in post-apartheid South Africa. Economic Modelling, 23(5): 805-821. 
Cameron, L., Chaudhuri, A., Erkal, N., \& Gangadharan, L. 2009. Propensities to engage in and punish corrupt behavior: Experimental evidence from Australia, India, Indonesia and Singapore. Joumal of Public Economics, 93(7-8): 843-851.

Carpenter, J., Daniere, A., \& Takahashi, L. 2004. Cooperation, trust, and social capital in Southeast Asian urban slums. Journal of Economic Behavior \& Organization, 55(4): 533-551.

Cason, T. N., Saijo, T., \& Yamato, T. 2002. Voluntary participation and spite in public good provision experiments: An international comparison. Experimental Economics, 5(2): 133-153.

Castro, F. M. 2008. Where are you from? Cultural differences in public good experiments. Journal of Socio-Economics, 37(6): 2319-2329.

Charness, G., \& Rabin, M. 2002. Understanding social preferences with simple tests. Quarterly Joumal of Economics, 117(3): 817-869.

Chen, C. C., Chen, X. P., \& Huang, S. 2013. Chinese guanxi: An integrative review and new directions for future research. Management and Organization Revieze, 9(1): 167-207.

Chen, K., \& Tang, F.-F. 2009. Cultural differences between Tibetans and ethnic Han Chinese in ultimatum bargaining experiments. European Journal of Political Economy, 25(1): 78-84.

Chen, X. P., \& Li, S. 2005. Cross-national differences in cooperative decision-making in mixedmotive business contexts: The mediating effect of vertical and horizontal individualism. Journal of International Business Studies, 36(6): 622-636.

Chen, Y., \& Mengel, F. 2016. Social identity and discrimination: Introduction to the special issue. European Economic Revieze, 90: 1-3.

Chowdhury, S. M., Jeon, J. Y., \& Ramalingam, A. 2016. Identity and group conflict. European Economic Revieze, 90: 107-121.

Chua, R. Y., \& Ng, K. Y. 2017. Not just how much you know: Interactional effect of cultural knowledge and metacognition on creativity in a global context. Management and Organization Revieze, 13(2): 281-300.

Chuah, S. H., Fahoum, R., \& Hoffmann, R. 2013. Fractionalization and trust in India: A fieldexperiment. Economics Letters, 119(2): 191-194.

Chuah, S. H., Gächter, S., Hoffmann, R., \& Tan, J. H. 2016. Religion, discrimination and trust across three cultures. European Economic Revieze, 90: 280-301.

Chuah, S. H., Hoffmann, R., Jones, M., \& Williams, G. 2007. Do cultures clash? Evidence from cross-national ultimatum game experiments. Journal of Economic Behavior \& Organization, 64(1): 35-48.

Chuah, S. H., Hoffmann, R., Jones, M., \& Williams, G. 2009. An economic anatomy of culture: Attitudes and behaviour in inter- and intra-national ultimatum game experiments. Journal of Economic Psychology, 30(5): 732-744.

Chuah, S. H., Hoffmann, R., Ramasamy, B., \& Tan, J. H. 2014. Religion, ethnicity and cooperation: An experimental study. Journal of Economic Psychology, 45: 33-43.

Cortina, J. M., \& Landis, R. S. 2009. When small effect sizes tell a big story, and when large effect sizes don't. In C. E. Lance \& R. J. Vandenberg (Eds.), Statistical and methodological myths and urban legends: Doctrine, verity, and fable in the organizational and social sciences: 287-308. New York: Routledge.

Cox, T. H., Lobel, S. A., \& McLeod, P. L. 1991. Effects of ethnic group cultural differences on cooperative and competitive behavior on a group task. Academy of Management Journal, 34(4): 827-847.

Croson, R., \& Donohue, K. 2006. Behavioral causes of the bullwhip effect and the observed value of inventory information. Management Science, 52(3): 323-336.

Falk, A., \& Fischbacher, U. 2006. A theory of reciprocity. Games and Economic Behavior, 54(2): 293-315.

Fan, Y. 2002. Questioning guanxi: Definition, classification and implications. International Business Reviez, 11(5): 543-561.

Fan, Y. 2007. Guanxi's consequences: Personal gains at social cost. Journal of Business Ethics, 38 (4): $371-380$.

Fang, T. 2009. Asian management research needs more self-confidence: Reflection on Hofstede (2007) and beyond. Asia Pacific Journal of Management, 27(1): 155-170.

Fang, T. 2012. Yin yang: A new perspective on culture. Management and Organization Revieze, 8(1): 25-50.

Fehr, E., \& Fischbacher, U. 2004. Third-party punishment and social norms. Evolution and Human Behavior, 25(2): 63-87.

Fehr, E., \& Gächter, S. 1998. Reciprocity and economics: The economic implications of homo reciprocans. European Economic Revieze, 42(3): 845-859. 
Fehr, E., \& Gächter, S. 2000. Fairness and retaliation: The economics of reciprocity. Jourmal of Economic Perspectives, 14(3): 159-181.

Fehr, E., Kirchsteiger, G., \& Riedl, A. 1993. Does fairness prevent market clearing? An experimental investigation. Quarterly Journal of Economics, 108(2): 437-459.

Fehr, E., \& Schmidt, K. M. 1999. A theory of fairness, competition, and cooperation. Quarterly Joumal of Economics, 114(3): 817-868.

Fershtman, C., \& Gneezy, U. 2001. Discrimination in a segmented society: An experimental approach. The Quarterly Journal of Economics, 116(1): 351-377.

Fershtman, C., Gneezy, U., \& Verboven, F. 2005. Discrimination and nepotism: The efficiency of the anonymity rule. Journal of Legal Studies, 34(2): 371-396.

Gächter, S. 2009. Improvements and future challenges for the research infrastructure in the field experimental economics. Working Paper 56. Berlin: Council for Social and Economic Data (RatSWD).

Gächter, S., \& Herrmann, B. 2009. Reciprocity, culture and human cooperation: Previous insights and a new cross-cultural experiment. Philosophical Transactions of the Royal Society B Biological Sciences, 364(1518): 791-806.

Gelfand, M. J., Higgins, M., Nishii, L. H., Raver, J. L., Dominguez, A., Murakami, F., Yamaguchi, S., \& Toyama, M. 2002. Culture and egocentric perceptions of fairness in conflict and negotiation. Journal of Applied Psychology, 87(5): 833-845.

Gerhart, B. 2009. How much does national culture constrain organizational culture? Management and Organization Revieze, 5(2): 241-259.

Glass, G. V., McGaw, B., \& Smith, M. L. 1981. Metaanalysis in social research. Beverly Hills, CA: Sage.

Greiner, B., Caravella, M., \& Roth, A. E. 2014. Is avatar-to-avatar communication as effective as face-to-face communication? An ultimatum game experiment in first and second life. Journal of Economic Behavior \& Organization, 108: 374-382.

Guthrie, D. 1998. The declining significance of guanxi in China's economic transition. The China Quarterly, 154(1): 254-282.

Hall, E. 1959. The silent language. New York: Anchor Press.

Harzing, A. W. 2007. Publish or perish. Retrieved from http://www.harzing.com/pop.htm.

Hennig-Schmidt, H., Li, Z.-Y., \& Yang, C. 2008. Why people reject advantageous offers - Nonmonotonic strategies in ultimatum bargaining. Evaluating a video experiment run in PR China. Journal of Economic Behavior \& Organization, 65(2): 373-384.

Henrich, J. 2000. Does culture matter in economic behavior? Ultimatum game bargaining among the Machiguenga of the Peruvian Amazon. American Economic Revieze, 90(4): 973-979.

Henrich, J., Heine, S. J., \& Norenzayan, A. 2010. The weirdest people in the world? Behavioral and Brain Sciences, 33(2-3): 61-83.

Henrich, J., Boyd, R., Bowles, S., Camerer, C., Fehr, E., Gintis, H., \& McElreath, R. 2001. In search of homo economicus: Behavioral experiments in 15 small-scale societies. American Economic Reviez, 91(2): 73-78.

Henrich, J., Ensminger, J., McElreath, R., Barr, A., Barrett, C., Bolyanatz, A., Cardenas, J. C., Gurven, M., Gwako, E., Henrich, N., Lesorogol, C., Marlowe, F., Tracer, D., \& Ziker, J. 2010. Markets, religion, community size, and the evolution of fairness and punishment. Science, 327(5972): 1480-1484.

Henrich, J., McElreath, R., Barr, A., Ensminger, J., Barrett, G., Bolyanatz, A., (...) \& Ziker, J. 2006. Costly punishment across human societies. Science, 312(5781): 1767-1770.

Herrmann, B., Thöni, G., \& Gächter, S. 2008. Antisocial punishment across societies. Science, 319 (5868): 1362-1367.

Hirai, M. 2000. Stereotypes about the Japanese: Differences in evaluations between 'the Japanese' and 'myself'. Japanese Journal of Experimental Social Psychology, 39: 103-113.

Ho, D. Y. F. 1996. Filial piety and its psychological consequences. In M. H. Bond (Ed.), The handbook of Chinese psychology: 155-165. Hong Kong: Oxford University Press.

Ho, D. Y. F., \& Lee, L. Y. 1974. Authoritarianism and attitude toward filial piety in Chinese teacher. Journal of Social Psychology, 92(2): 305-306.

Hoffman, E., McCabe, K., \& Smith, V. 2008. Reciprocity in ultimatum and dictator games: An introduction. In C. R. Plott \& V. L. Smith (Eds.), Handbook of experimental economics results (1): 411-416. Amsterdam: North-Holland/Elsevier.

Hofstede, G. 1980. Culture's consequences - International differences in work related values. Newbury Park, London, New Delhi: Sage.

Hofstede, G. 1991. Cultures and organizations: Software of the mind. New York: McGraw-Hill.

(C) 2018 The International Association for Chinese Management Research 
Horak, S. 2016. Decision-making behavior, gender differences, and cultural context variables. International Journal of Cross Cultural Management, 16(3): 281-299.

Johansson-Stenman, O., Mahmud, M., \& Martinsson, P. 2009. Trust and religion: Experimental evidence from rural Bangladesh. Economica, 76(303): 462-485.

Johansson-Stenman, O., Mahmud, M., \& Martinsson, P. 2013. Trust, trust games and stated trust: Evidence from rural Bangladesh. Journal of Economic Behavior \& Organization, 95: 286-298.

Jones, E. L. 2006. Cultures merging: A historical and economic critique of culture. New Jersey: Princeton University Press.

Jung, D. I., \& Avolio, B. J. 1999. Effects of leadership style and followers' cultural orientation on performance in group and individual task conditions. Academy of Management Journal, 42(2): 208-218.

Kahneman, D., Knetsch, J. L., \& Thaler, R. 1986. Fairness as a constraint on profit seeking: Entitlements in the market. American Economic Review, 76(4): 728-741.

Kirkman, B. L., Lowe, K. B., \& Gibson, C. B. 2006. A quarter century of culture's consequences: A review of empirical research incorporating Hofstede's cultural values framework. Journal of International Business Studies, 37(3): 285-320.

Koch, B. J., \& Koch, P. T. 2007. Collectivism, individualism, and outgroup cooperation in a segmented China. Asia Pacific Journal of Management, 24(2): 207-225.

Kocher, M., Cherry, T., Kroll, S., Netzer, R., \& Sutter, M. 2008. Conditional cooperation on three continents. Economics Letters, 101(3): 175-178.

Lee, D. Y., \& Dawes, P. L. 2005. Guanxi , trust, and long-term orientation in Chinese business markets. Journal of International Marketing, 13(2): 28-56.

Leung, K. 2012. Indigenous Chinese management research: Like it or not, we need it. Management and Organization Reviere, 8(1): 1-5.

Leung, K., \& Su, S. K. 2004. Experimental methods for research on culture and management. In B. J. Punnett \& O. Shenkar (Eds.), Handbook for international management research: 68 97. Ann Arbor: University of Michigan Press.

Leung, K., Bhagat, R. S., Buchan, N. R., Erez, M., \& Gibson, C. B. 2005. Culture and international business: Recent advances and their implications for future research. Journal of International Business Studies, 36(4): 357-378.

Lewin, A. Y., Chiu, C. Y., Fey, C. F., Levine, S. S., McDermott, G., Murmann, J. P., \& Tsang, E. 2016. The critique of empirical social science: New policies at Management and Organization Review. Management and Organization Review, 12(4): 649-658.

Li, P. P. 2015. Both converging toward and diverging from global paradigms: The perspective of YinYang balancing for the unity-in-diversity duality. Management and Organization Reviez, 11(4): 807-813.

Li, P. P., Leung, K., Chen, C. C., \& Luo, J. D. 2012. Indigenous research on Chinese management: What and how. Management and Organization Revieze, 8(1): 7-24.

Lin, N. 2002. How the East and the West shall meet. Development and Society, 31(2): 211-244.

Lönnqvist, J. E., Verkasalo, M., Walkowitz, G., \& Wichardt, P. C. 2015. Measuring individual risk attitudes in the lab: Task or ask? An empirical comparison. Journal of Economic Behavior \& Organization, 119: 254-266.

Lönnqvist, J. E., Walkowitz, G., Verkasalo, M., \& Wichardt, P. G. 2011. Situational power moderates the influence of self-transcendence vs. self-enhancement values on behavior in ultimatum bargaining. Journal of Research in Personality, 45(3): 336-339.

Lönnqvist, J. E., Walkowitz, G., Wichardt, P., Lindeman, M., \& Verkasalo, M. 2009. The moderating effect of conformism values on the relations between other personal values, social norms, moral obligation, and single altruistic behaviours. British Journal of Social Psychology, 48(3): 525-546.

Luo, Y. 2008. The changing Chinese culture and business behavior: The perspective of intertwinement between guanxi and corruption. International Business Review, 17(2): 188-193.

Ma, D. 2012. A relational view of organizational restructuring: The case of transitional China. Management and Organization Review, 8(1): 51-75.

Maciejovsky, B., Kirchler, E., \& Schwarzenberger, H. 2007. Misperception of chance and loss repair: On the dynamics of tax compliance. Journal of Economic Psychology, 28(6): 678-691.

Morris, S. B., \& DeShon, R. P. 1997. Correcting effect sizes computed from factor analysis of variance for use in meta-analysis. Psychological Methods, 2(2): 192-199.

Morris, S. B., \& DeShon, R. P. 2002. Combining effect size estimates in meta-analysis with repeated measures and independent-groups designs. Psychological Methods, 7(1): 105-125. 
Ockenfels, A., \& Weimann, J. 1999. Types and patterns: An experimental East-West-German comparison of cooperation and solidarity. Journal of Public Economics, 71(2): 275-287.

Ohbuchi, K., \& Saito, T. 2007. Cognitive causes of conflict avoidance among Japanese: An approach from pluralistic ignorance. Progress in Asian Social Psychology, 6: 83-97.

Onwuegbuzie, A. J. 2003. Effect sizes in qualitative research: A prolegomenon. Quality and Quantity, 37(4): 393-409.

Oosterbeek, H., Sloof, R., \& Van De Kuilen, G. 2004. Cultural differences in ultimatum game experiments: Evidence from a meta-analysis. Experimental Economics, 7(2): 171-188.

Opper, S., Nee, V., \& Holm, H. J. 2017. Risk aversion and guanxi activities: A behavioral analysis of CEOs in China. Academy of Management Joumal, 60(4): 1504-1530.

Ottone, S., Ortona, G., Ponzano, F., \& Scacciati, F. 2010. Some differences in revealed behaviour under different inquiry methods. The Journal of Socio-Economics, 39(5): 546-553.

Rabin, M. 1993. Incorporating fairness into game theory and economics. American Economic Revieze, 83(5): 1281-1302.

Ray, J. W., \& Shadish, W. R. 1996. How interchangeable are different estimators of effect size? Journal of Consulting and Clinical Psychology, 64(6): 1316-1325.

Roth, A. E. 1995. Introduction to experimental economics. In J. H. Kagel \& A. E. Roth (Eds.), The handbook of experimental economics: 1-98. Princeton, NJ: Princeton University Press.

Roth, A. E., Prasnikar, V., Okuno-Fujiwara, M., \& Zamir, S. 1991. Bargaining and market behavior in Jerusalem, Ljubljana, Pittsburgh, and Tokyo: An experimental study. American Economic Revieze, 81(5): 1068-1095.

Schwartz, S. H., Melech, G., Lehmann, A., Burgess, S., Harris, M., \& Owens, V. 2001. Extending the cross-cultural validity of the theory of basic human values with a different method of measurement. Journal of Cross-Cultural Psychology, 32(5): 519-542.

Sears, D. O. 1986. College sophomores in the laboratory: Influences of a narrow data base on social psychology's view of human nature. Journal of Personality and Social Psychology, 51(3): 515-530.

Sigmund, V. K., Fehr, E., \& Nowak, M. A. 2002. Teilen und helfen - ursprünge sozialen verhaltens. Spektrum Der Wissenschaft, März 2002: 52-59.

Smith, V. L., \& Walker, J. M. 1993. Monetary rewards and decision cost in experimental economics. Economic Inquiry, 31(2): 245-261.

Song, F., Cadsby, C. B., \& Bi, Y. 2012. Trust, reciprocity, and guanxi in China: An experimental investigation. Management and Organization Revieze, 8(2): 397-421.

Stiglitz, J. 2002: Information and the change in the paradigm in economics. American Economic Revieze, 92(3): 460-501.

Thaler, R. H. 1988. Anomalies: The ultimatum game. Journal of Economic Perspectives, 2(4): 195-206.

Tsui, A. S. 2004. Contributing to global management knowledge: A case for high quality indigenous research. Asia Pacific Joumal of Management, 21(4): 491-513.

Tsui, A. S. 2007. From homogenization to pluralism: International management research in the academy and beyond. Academy of Management Joumal, 50(6): 1353-1364.

Valenzuela, A., Srivastava, J., \& Lee, S. 2005. The role of cultural orientation in bargaining under incomplete information: Differences in causal attributions. Organizational Behavior and Human Decision Processes, 96(1): 72-88.

Van de Ven, A. H., \& Jing, R. 2012. Indigenous management research in China from an engaged scholarship perspective. Management and Organization Revieze, 8(1): 123-137.

Van Witteloostuijn, A. 2015. Toward experimental international business: Unraveling fundamental causal linkages. Cross-Cultural and Strategic Management, 22(4): forthcoming. doi: 10.1108/CCM-06-2015-0075.

Weber, R. A., \& Camerer, C. F. 2006. Behavioral experiments in economics. Experimental Economics, 9(3): 187-192.

Weimann, J. 1994. Individual behaviour in a free riding experiment. Journal of Public Economics, 54(2): 185-200.

Werner, S. 2002. Recent developments in international management research: A review of 20 top management journals. Journal of Management, 28(3): 277-305.

Wu, M., Huang, X., Li, C., \& Liu, W. 2012. Perceived interactional justice and trust-in-supervisor as mediators for paternalistic leadership. Management and Organization Revieze, 8(1): 97-121.

Yamagishi, T., Hashimoto, H., \& Schug, J. 2008. Preferences versus strategies as explanations for culture-specific behavior. Psychological Science, 19(6): 579-84.

(C) 2018 The International Association for Chinese Management Research 
Yamagishi, T., Jin, N., \& Kiyonari, T. 1999. Bounded generalized reciprocity: Ingroup favoritism and ingroup boasting. Advances in Group Processes, 16: 161-197.

Yamagishi, T., Terai, S., Kiyonari, T., Mifune, N., \& Kanazawa, S. 2007. The social exchange heuristic: Managing errors in social exchange. Rationality and Society, 19(3): 259-291.

Yen, D. A., Barnes, B. R., \& Wang, C. L. 2011. The measurement of guanxi: Introducing the GRX scale. Industrial Marketing Management, 40(1): 97-108.

Yi, L. M., \& Ellis, P. 2000. Insider-outsider perspectives of guanxi. Business Horizons, 43(1): 25-30.

Zhao, S., \& Jiang, C. 2009. Learning by doing: Emerging paths of Chinese management research. Management and Organization Revieze, 5(1): 107-119.

Zolkiewski, J. M., \& Feng, J. 2012. Relationship portfolios and guanxi in Chinese business strategy. Journal of Business \& Industrial Marketing, 27(1): 16-28.

Sven Horak (horaks@stjohns.edu) (PhD, Duisburg-Essen University, Germany) is an associate professor at The Peter J. Tobin College of Business of the St. John's University in New York City, where he researches and teaches in the area of international management and organization. His research interests include the analysis of informal practices and network structures, interpersonal relationships and social ties, informal management, socio-cultural aspects of management, and Asian business and management.

Manuscript received: $\quad$ May 21, 2017

Final version accepted: August 31, 2018 (number of revisions - 3)

Accepted by: $\quad$ Senior Editor Peter Ping Li 